\title{
Multi-scale interactions in a high-resolution tropical-belt experiment and observations
}

\author{
Ricardo Fonseca ${ }^{1,3}$ (1) $\cdot$ Tieh-Yong Koh ${ }^{2,3} \cdot$ Chee-Kiat Teo ${ }^{4,5}$
}

Received: 9 November 2017 / Accepted: 26 June 2018 / Published online: 3 July 2018

(c) The Author(s) 2018

\begin{abstract}
The Weather Research and Forecasting (WRF) model is used to dynamically downscale 27 years of the Climate Forecast System Reanalysis (CFSR) in a tropical belt configuration at $36 \mathrm{~km}$ horizontal grid spacing. WRF is found to give a good rainfall climatology as observed by the Tropical Rainfall Measuring Mission (TRMM) and to reproduce well the largescale circulation and surface radiation fluxes. The impact of conventional and Modoki-type El Niño-Southern Oscillation (ENSO) and the Indian Ocean Dipole (IOD) are confirmed by linear regression. Madden-Julian Oscillation (MJO) and Boreal Summer Intra-seasonal Oscillation (BSISO) are also well-simulated. The WRF simulation shows that conventional El Niño increases (La Niña decreases) the MJO amplitude in the boreal summer while Modoki-type ENSO and IOD impacts are MJO-phase dependent. While WRF is found to perform well on seasonal to sub-seasonal timescales, it does not capture well the diurnal cycle of precipitation over the Maritime Continent. For the investigation of multi-scale interactions through the local diurnal cycle, TRMM data is used instead. In the Maritime Continent, moderate El Niño and La Niña causes antisymmetric enhancement/reduction of the MJO's influence on the diurnal cycle amplitudes with little change in the diurnal phase. Non-linear impacts on the diurnal amplitude with changes in diurnal phase manifest during strong ENSO. Given that the simulation does not employ data assimilation, this modified version of WRF submitted to the model developers is a suitable downscaling tool of CFSR for sub-seasonal to seasonal tropical atmospheric research.
\end{abstract}

\section{Introduction}

General circulation models (GCMs), given their coarse horizontal resolution that does not allow for a proper representation of the regional topography, often fail to simulate many

Electronic supplementary material The online version of this article (https://doi.org/10.1007/s00382-018-4332-y) contains supplementary material, which is available to authorized users.

Tieh-Yong Koh

tykoh@suss.edu.sg

1 Division of Space Technology, Department of Computer Science, Electrical and Space Engineering, Luleå University of Technology, Luleå, Sweden

2 UC, Singapore University of Social Sciences, Singapore, Singapore

3 Earth Observatory of Singapore, Nanyang Technological University, Singapore, Singapore

4 Centre for Climate Research Singapore, Meteorological Services Singapore, Singapore, Singapore

5 Centre for Applied Research, Singapore University of Social Sciences, Singapore, Singapore of the factors and processes that drive regional and local climate variability. This partially explains why important aspects of convection in the tropics, such as the interaction of the large-scale convection (e.g. that associated with the Madden-Julian Oscillation, MJO) with the tropical topography (Hsu and Lee 2005; Tseng et al. 2017) and the diurnal cycle (Peatman et al. 2015), are not well captured. These problems can be overcome with Regional Climate Models (RCMs) that require much less computational resources to run at higher horizontal resolutions meaning that the complex topography and land-sea mask will be better represented (Wang et al. 2004; Laprise 2008; Tan et al. 2018).

An alternative to the use of RCMs are high-resolution observational datasets but these also have limitations in particular their short temporal duration. For example, and focusing on precipitation, the Tropical Precipitation Measuring Mission 3B42 (TRMM; Huffman et al. 2007) dataset is available at $0.25^{\circ} \times 0.25^{\circ}(\sim 27 \mathrm{~km})$ every $3 \mathrm{~h}$ but only from 1998 while the $\sim 8 \mathrm{~km}$ National Oceanic and Atmospheric Administration Climate Prediction Center Morphing Technique (CMORPH; Joyce et al. 2004) that provides $30 \mathrm{~min}$ precipitation estimates is only available from 2002 . What is 
more, measurements of one particular (and normally twodimensional, 2D) field, such as precipitation, 10-m wind or 2-m temperature, may not be in dynamical consistency with the analyses and measurements from other observational platforms. Three-dimensional (3D) dynamic fields such as heating and moistening rates that are needed in order to have a complete understanding of the large-scale circulation are not observed and must be retrieved as model analysis products.

The lack of high-quality observations in the tropics means that most of the gridded datasets, including the ones referred above, contain much more model input (which may have substantial errors, e.g. Adler et al. 2001) than observation input. This problem is particularly true for wind which is a crucial variable in tropical dynamics, more important than the mass field (Žagar et al. 2004). Data assimilation attempts may also be hampered by the dearth of high-quality observations. Hence, a high resolution model run in the global tropics that verifies well against observations and extends over a considerable period of time may not be worse than a high-resolution gridded dataset and may be even be preferred as a dynamically consistent and more comprehensive atmospheric dataset that can be used to investigate regional climate features. The creation of such a dataset for future studies is one important motivation of this work.

There have been attempts to run RCMs in a tropical belt configuration focusing primarily on the MJO: e.g. Ray et al. (2009) used the Penn State/National Center for Atmospheric Research Mesoscale Model (MM5; Grell et al. 1995) to study the MJO initiation for two observed cases and found that providing realistic time-varying lateral boundary conditions is crucial for the model to simulate the MJO events. Ray et al. (2011) used the Weather Research and Forecasting Model (WRF; Skamarock et al. 2008) to investigate the role of the atmospheric mean state on the initiation of the MJO. In that work WRF was run for 5 years with a horizontal grid spacing of $36 \mathrm{~km}$ and with different configurations and it was found that in the RCM the MJO was no better simulated than in coarse resolution GCMs mainly due to an error in the mean state. More recently Ulate et al. (2015) stressed the importance of capturing the water vapour distribution for the model to simulate well the MJO. The need to get the moisture correct is also highlighted in Hagos et al. (2011). Tulich et al. (2011) performed a 6-year WRF run at $36 \mathrm{~km}$ horizontal grid spacing with the aim of examining how well convectively-coupled Kelvin and easterly waves were simulated by the model. The authors found a good agreement between the simulated and observed wave structures although Kelvin waves were found to be underactive throughout the tropics and easterly waves are overactive in the Pacific but relatively inactive elsewhere. Further analysis showed this to be a result of a strong coupling of convection to rotational circulation anomalies in WRF. Seo et al. (2014) conducted coupled ocean-atmosphere simulations focusing on a MJO event in late 2011 and found that a correct representation of the diurnal SST variability is crucial for the model to simulate the MJO. In all the studies mentioned above the model was run for just a few years.

Longer runs in a tropical belt have been performed but at coarser spatial resolutions of about $80 \mathrm{~km}$ or lower such as in Vitart and Jung (2010), Ray and Li (2013) and Hall et al. (2017) that focused on the role of the extratropics on the MJO. However, if the focus is on tropical inter-annual variability of intra-seasonal oscillations, the RCM has to be run for a longer period of time and at higher spatial resolutions. In this work a version of the WRF model modified for the tropics (Fonseca et al. 2015; Koh and Fonseca 2016) is run for 27 -years at $36 \mathrm{~km}$ horizontal grid spacing in a tropical belt configuration to downscale the regional impacts of the El Niño-Southern Oscillation (ENSO) and the Indian Ocean Dipole (IOD) in the tropics as well as how to investigate how they interact with the MJO and the Boreal Summer Intraseasonal Oscillation (BSISO).

Intra-seasonal Oscillations (ISOs) are fluctuations of winds and convection that control much of the large-scale variability in the tropics on timescales of about 15-100 days. The MJO is the dominant mode of variability in the tropical atmosphere on 30-90 day timescales and planetary spatial scales. It is characterized by eastward propagating regions of enhanced and suppressed rainfall across the tropics (Madden and Julian 1971, 1972, 1994). In the boreal summer season over the Asian monsoon region, the convection is centred in the northern tropics and its intra-seasonal variability is not properly captured by the conventional MJO which straddles the equator. Another characterization, the BSISO, is normally invoked in the Asian region (Wang and Xie 1997; Lee et al. 2013). ENSO is a pattern of variability of the climate system with irregular periods of the order of 3-7 years and decadal variations. There are warm (El Niño) and cold (La Niña) events corresponding to warmer or colder sea surface temperature (SST) over the central and eastern equatorial Pacific, respectively, with typical SST anomaly amplitudes of $1-4{ }^{\circ} \mathrm{C}$ (Rasmusson and Carpenter 1982). ENSO has been shown to have impacts across the whole tropics (e.g. Philander 1990; Dilley and Heyman 1995; Dai and Wigley 2000; Mason and Goddard 2001) and in Southeast Asia it can lead to very different regional responses in particular in the boreal winter monsoon season (Lee and McBride 2016; Jiang and Li 2017; Tangang et al. 2017). Recent research has shown that since the late 1970s El Niño events have often manifested a different SST structure from conventional El Niños: instead of increased SSTs in the eastern tropical Pacific, the maximum SST anomalies are found in the central Pacific with anomalous cooling to the east and to the west (Ashok et al. 2007; Ashok and Yamagata 2009). These events, called El Niño Modoki events, have different global impacts (e.g. Weng et al. 
2009) and will also be considered here. The IOD, also called Indian Ocean Zonal Mode, is a coupled ocean-atmospheric pattern of variability characterized by an irregular oscillation of the SSTs in the Indian Ocean with positive (negative) phases associated with above-average SSTs in the western (eastern) Indian Ocean and below-average SSTs in the eastern (western) Indian Ocean (Saji et al. 1999). This mode has been shown to directly affect the regional climate of the Maritime Continent (Saji and Yamagata 2003) and its impacts will be investigated in this study. It is important to note that the two patterns of variability, ENSO and IOD, are not independent. In fact, IOD events can be initiated by ENSO events and can also result from processes internal to the Indian Ocean associated with the Asian-Australian monsoon (e.g. Fischer et al. 2005; Behera and Yamagata 2003; Behera et al. 2006). MJO activity is modulated by the ENSO and IOD and this crossscale interaction will have important implications for regional weather and climate prediction and is one foci of this paper.

The WRF model, used in this work, is a community model used in a wide variety of applications including coupled-model applications (Samala et al. 2013), idealized simulations (Steele et al. 2013), tropical cyclone research (Davis et al. 2008) and regional climate research (Chotamonsak et al. 2011, 2012). Here it is used to investigate how interannual modes of variability, ENSO and IOD especially in their "unusual" co-occurrences, impact the regional seasonal climate in the tropics, and how tropical modes of intra-seasonal variability, MJO and the BSISO, manifest under different ENSO and IOD conditions. At the shorter timescale, we investigate how the mean diurnal cycle changes under combined ENSO-MJO influence with observation datasets.

In Sect. 2 details about the model setup and methods used are given. The results of the model evaluation against observations are presented in Sect. 3 while the impact of ENSO and IOD on the climate of the global tropics is briefly discussed in Sect. 4. Section 5 is the focus of this work: we diagnose the MJO and BSISO in the model and show how they interact with ENSO and IOD. Emphasis is also placed on how the MJO together with ENSO modulate the diurnal cycle of precipitation in Southeast Asia. The main conclusions are summarized in Sect. 6.

\section{Model, datasets and diagnostics}

\subsection{Numerical model}

WRF is a fully compressible, non-hydrostatic numerical model that uses a terrain-following vertical coordinate based on the hydrostatic pressure component and Arakawa-C grid staggering for horizontal discretization. In this study, WRF version 3.3.1 is run for 27 years (April 1988-March 2015) with boundary conditions from the National Centers for Environmental Prediction (NCEP) Climate Forecast System Reanalysis (hereafter CFSR; Saha et al. 2010) 6-h data (horizontal resolution of $0.5^{\circ} \times 0.5^{\circ}$ ). Following Lo et al. (2008), and in order to reduce the accumulation of integration errors, the run is broken into overlapping 13-month periods (00 UTC, 1st March of year X to 00 UTC, 1st April of year $\mathrm{X}+1$ ) with the first month discarded as model spin-up after (re-)initialization with CFSR data. The (re-)initialization is carried out in the boreal spring to lessen any potential influence of the spring predictability barrier associated with ENSO on our simulation while keeping the conventional boreal winter monsoon period (Dec-Mar) intact within one continuous integration. The physics parameterizations used include the Goddard six-class microphysics scheme (GSFC; Tao et al. 1989), the Rapid Radiative Transfer Model for Global models (RRTMG) for both short-wave and longwave radiation (Iacono et al. 2008), the Yonsei University Planetary Boundary Layer (PBL) scheme (Hong et al. 2006), the Monin-Obukhov surface layer parameterization (Monin and Obukhov 1954) and the four-layer Noah land surface model (Chen and Dudhia 2001). The Betts-Miller-Janjić (BMJ) scheme (Janjić 1994) was employed and adapted for the tropical deep convection (Fonseca et al. 2015). In order to account for cumulus cloud-radiation feedback, the Precipitating Convective Cloud (PCC) scheme (Koh and Fonseca 2016) developed for use with the BMJ scheme was employed. The radiation scheme was called every $10 \mathrm{~min}$ or 5 model time-steps which corresponds to the zenith sun migrating across $2.5^{\circ}$ of longitude or 7-8 grid-points. We consider this as minimally necessary to capture well the diurnally modulated radiative-convective dynamics at regional scales which is key to simulating the global tropics without over-consuming computational resources. This is even more pertinent to effects arising from land-sea contrasts in the Maritime Continent which have land masses with zonal spans ranging from about $2.5^{\circ}-10^{\circ}$. In all model experiments seasonally dependent vegetation fraction and surface albedo are used. A simple interactive prognostic scheme for the sea surface skin temperature (SSKT) based on Zeng and Beljaars (2005), which takes into account the effects of the sensible, latent and radiative fluxes as well as molecular diffusion and turbulent mixing, is incorporated with the model to capture the diurnal variation of the SSKT and its feedback to the atmosphere. The lower boundary condition to the SSKT-scheme comes from the 6-h SST data from CFSR, linearly interpolated in time in order to have a continuously varying forcing on the sea surface skin layer. The meridional boundary conditions from CFSR are relaxed on a ten grid-point buffer zone (not displayed in the figures), while the zonally periodic condition is applied along the prime meridian.

The tropical belt domain, shown in Fig. 1a, is used in the model experiments. The domain extends from about $36^{\circ} \mathrm{S}$ to $46^{\circ} \mathrm{N}$ with a horizontal grid spacing of $36 \mathrm{~km}$ to 
(a)

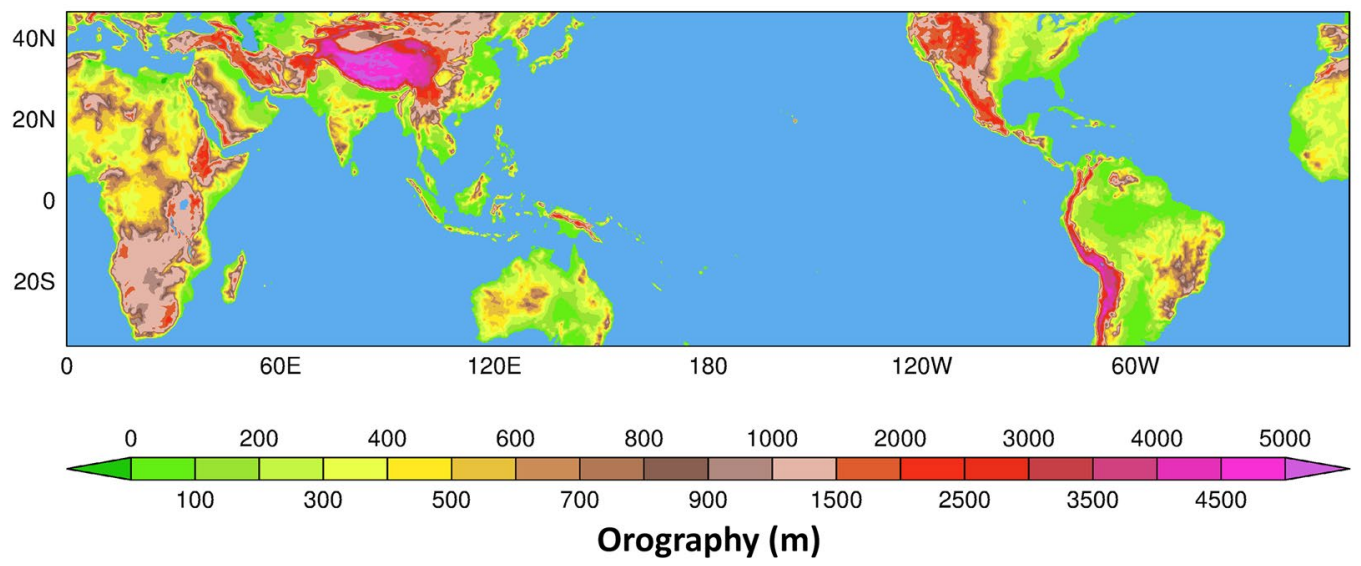

(b)

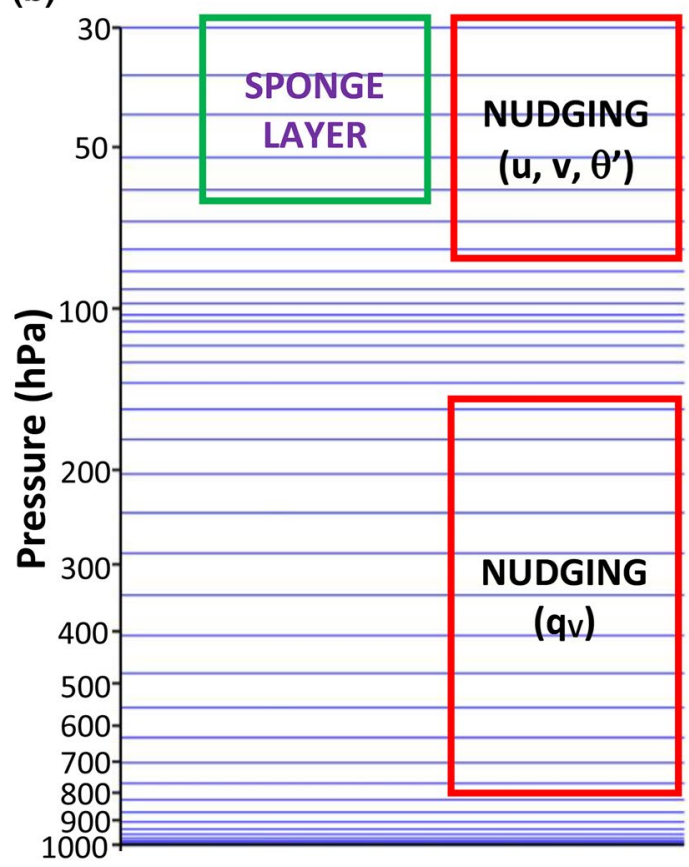

(c)

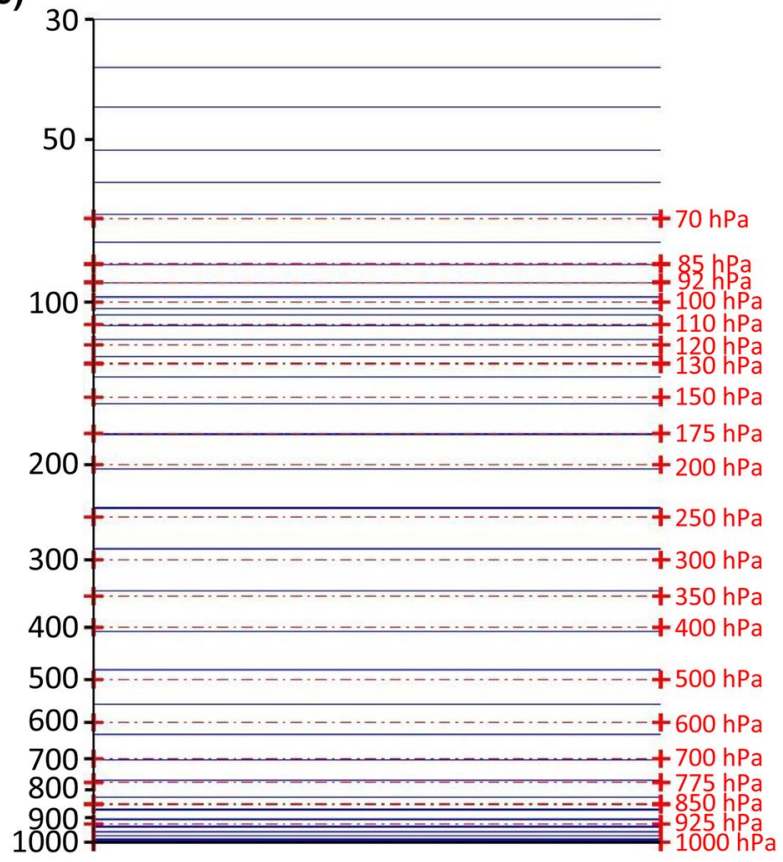

Fig. 1 a Model domain orography (m), b model (eta) levels with the nudging regions and sponge layer highlighted in red and green rectangles, respectively, and $\mathbf{c}$ model (eta) levels and output (pressure) levels. The vertical coordinate in $\mathbf{b}, \mathbf{c}$ is in logarithmic scale

cover all major monsoon regions. The static fields, including the topography, used in the experiments are carefully interpolated from a $\sim 900 \mathrm{~m}$ dataset available on the model's website. Figure $1 \mathrm{~b}$ shows the model vertical levels: the 37 levels are spaced more closely apart in the tropical tropopause and PBL regions with the model top placed at $30 \mathrm{hPa}$. The levels in red boxes are where analysisnudging (a.k.a. grid-nudging) towards CFSR values is employed: the water vapour mixing ratio $\left(q_{v}\right)$ is nudged in the mid-troposphere while the horizontal winds $(u, v)$ and potential temperature perturbation $\left(\theta^{\prime}\right)$ are nudged in the lower stratosphere. The former is needed to correct the WRF model's tendency to overly moisten the atmosphere as a result of excessive surface evaporation in the subtropics (related to problems in low-cloud parameterization), whereas the latter is necessary for the model to capture the Quasi-Biennial Oscillation (QBO; Andrews et al. 1987; Saha et al. 2010). A good simulation of $q_{v}$ is necessary for the model to properly simulate the MJO (Hagos et al. 2011; Ulate et al. 2015). The nudging timescale is uniformly equal to $1 \mathrm{~h}$. In a paper currently under preparation the sensitivity of WRF's dynamical and thermodynamic fields to the nudging formulation in the tropics is investigated. The nudging approach used here is the one found to give the best results out of those considered. Regarding the nudging time-scale, it is found that increasing it leads 
to a poorer performance in fields such as precipitation and so it has to be kept short of about $1 \mathrm{~h}$ (not shown).

Although $q_{v}$ is nudged on a short timescale in the midtroposphere, an analysis of the precipitable water budget revealed that the nudging tendency is globally far from being the largest term (submitted as supplementary material). The dominant balance in the deep convective tropics is still between cumulus transport and horizontal flux convergence. In fact, it can be proven mathematically that the nudging is only effective in constraining the model climatology to CFSR (not shown). The nudging on the short timescale itself is noisy with zero net impact because the reference water vapour field from CFSR is itself varying on the same timescale. On the whole, this leaves an effective degree of freedom for the water vapour in WRF to fluctuate on the short timescale.

In Fonseca et al. (2015) the authors have modified the BMJ scheme so that the precipitation produced by WRF agrees with that observed as given by TRMM. This is achieved by reducing $\mathrm{F}_{S}$, a parameter that controls the reference humidity profile with smaller values of $F_{S}$ leading to a more moist profile, from its default value of 0.85 to 0.6 . As the nudging formulation used here is different, the referred modification is found to less optimal in the sense that WRF gives slightly excessive rainfall compared to TRMM. The optimal performance is recovered by increasing the parameter $\alpha_{\mathrm{BMJ}}$ that controls the reference temperature profile, with larger values of $\alpha_{\mathrm{BMJ}}$ leading to a warmer profile (cf. Fonseca et al. 2015, for details), from its default value of 0.9 to 0.1 while keeping $F_{S}$ at 0.6 . The optimization of the BMJ scheme is carried out for June-September (JJAS) 2008 and verified in December to March (DJFM) 2008-2009, a nonENSO non-IOD period.

The model output is linearly interpolated onto 21 pressure levels, shown in Fig. 1c, with a higher resolution in the tropical tropopause and PBL regions. The output frequency is $3 \mathrm{~h}$ from which four daily summary statistics, namely the mean, minimum, maximum and standard deviation, are computed. Due to data storage constraints, only 6-h output files and the daily summary statistics are archived. In addition, the 3-h precipitation rates are also archived.

\subsection{Datasets and verification diagnostics}

The model's surface radiative fluxes over the oceans are evaluated against the monthly mean fluxes from the National Oceanography Centre Southampton (NOCS) Version 2.0 dataset (spatial resolution of $1^{\circ} \times 1^{\circ}$; Berry and Kent 2009) while over land they are evaluated against the 6-h primarily model-derived radiative fluxes from CFSR with which WRF shares the same land surface model (Saha et al. 2010). The 2-m temperature is evaluated against the monthly-mean temperature given by the Global Historical
Climate Network version 2 and the Climate Anomaly Monitoring System (GHCN + CAMS) dataset (spatial resolution of $0.5^{\circ} \times 0.5^{\circ}$; Fan and van den Dool 2008) whereas the soil moisture is compared with the one given by the European Space Agency (ESA) Climate Change Initiative (CCI) soil moisture dataset (spatial resolution of $0.25^{\circ} \times 0.25^{\circ}$; Wagner et al. 2012). The precipitation rate is evaluated against that observed as given by TRMM (spatial resolution of $0.25^{\circ} \times 0.25^{\circ}$ ). The 10 -m horizontal winds from QuickSCAT produced by Remote Sensing Systems and sponsored by the National Aeronautics and Space Administration Ocean Vector Winds Science Team (spatial resolution of $0.25^{\circ} \times 0.25^{\circ}$; Riciardulli et al. 2011) as well as the SSTs from the UK Met Office Hadley Centre's SST dataset (HadISST1, spatial resolution of $1^{\circ} \times 1^{\circ}$; Rayner et al. 2003) are also used in this work. For the model evaluation the spatial resolution of the coarser of the two datasets is considered with the WRF outputs bilinearly interpolated to the $1^{\circ} \times 1^{\circ} \mathrm{NOCSv} 2$ and $0.5^{\circ} \times 0.5^{\circ}$ CFSR and GHCN + CAMS grids while the $0.25^{\circ} \times 0.25^{\circ}$ ESA CCSI soil moisture and TRMM precipitation are interpolated to the $36 \mathrm{~km}\left(\sim 0.32^{\circ}\right) \mathrm{WRF}$ grid.

The model's performance is assessed with different verification diagnostics including the model bias, normalized bias $(\mu)$, correlation $(\rho)$, variance similarity $(\eta)$ and normalized error variance $(\alpha)$ obeying the identity (1) below.

$\alpha \equiv 1-\rho \eta$

The bias is defined as the mean discrepancy between the model and observations while the normalized bias is given by the bias divided by the standard deviation of the discrepancy between the model and observations. The correlation is a measure of the phase agreement between the variation of the model and observed signals. The variance similarity is an indication of how well the signal variation amplitude simulated by the model agrees with that observed and is defined as the ratio of the geometric mean to the arithmetic mean of the modelled and observed variances. The normalized error variance is the variance of the error arising from the disagreement in phase and amplitude, normalized by the combined modelled and observed signal variances. The best model performance corresponds to zero bias and normalized bias, and zero normalized error variance $\alpha$ which requires that both correlation $\rho$ and variance similarity $\eta$ to be equal to 1 . This set of diagnostics are defined in Eqs. (14)-(19) in Appendix 1 and were developed in Koh and Ng (2009) and Koh et al. (2012). The root-mean-square error (RMSE) is determined by the normalized error variance and normalized bias as follows:

$R M S E^{2} \equiv \alpha\left(1+\mu^{2}\right)[\operatorname{var}(\boldsymbol{O})+\operatorname{var}(\boldsymbol{F})]$

where $\operatorname{var}(\boldsymbol{O})$ and $\operatorname{var}(\boldsymbol{F})$ refer to the variance of the observation and model forecast respectively. 
An additional set of diagnostics, taken from Feng et al. (2013) and Pascale et al. (2015), is used to evaluate how well the WRF model simulates the observed seasonality in the monthly precipitation: $S$, the monthly rainfall seasonality; $C$, the centroid of the rainfall distribution; $n^{\prime}$, the effective number of wet months. These diagnostics are defined in Eqs. (20)-(23) in Appendix 1.

\section{Model evaluation}

In this section the model's performance is evaluated against observations and re-analysis data. Figures 2 and 3 show the verification diagnostics for the precipitation rate (evaluated against TRMM) and the 200 and $850 \mathrm{hPa}$ horizontal wind vectors, $850 \mathrm{hPa}$ specific humidity and $500 \mathrm{hPa}$ temperature (evaluated against CFSR) for the boreal summer (JJAS) and winter (DJFM) monsoon seasons, respectively. The results for the two inter-monsoon seasons (April-May and October-November) are among the supplementary material (Figures S7 and S8). The evaluation is performed over the common period when the model and the observed/ re-analysis dataset overlap: January 1998-December 2010 for TRMM and April 1988-March 2015 for CFSR. Shown are the WRF mean, biases and normalized error variance $(\alpha)$ of time series of pentad means. As the variance similarity for all variables is always nearly 1 in our work, Eq. (1) implies the pattern of normalized error variance mainly follows that of the correlation diagnostic. Due to space constraints, the correlation diagnostics for all verified variables and, for illustration, the variance similarity diagnostic for rainfall are presented in the supplementary material. Note that none of the verified fields are nudged directly to CFSR data.

The model performance is similar for all seasons with comparable scores for all the diagnostics. The precipitation biases are rather small even though WRF is generally slightly drier over land compared to TRMM in particular in parts of South America and West Africa. It can be seen that regions with negative precipitation biases may sometimes have positive biases in the specific humidity at $850 \mathrm{hPa}$ (and vice-versa). The probable cause of these moisture biases is low-level moisture advection by the wind: e.g. in parts of northern South America where positive low-level moisture bias occur, the southerly wind

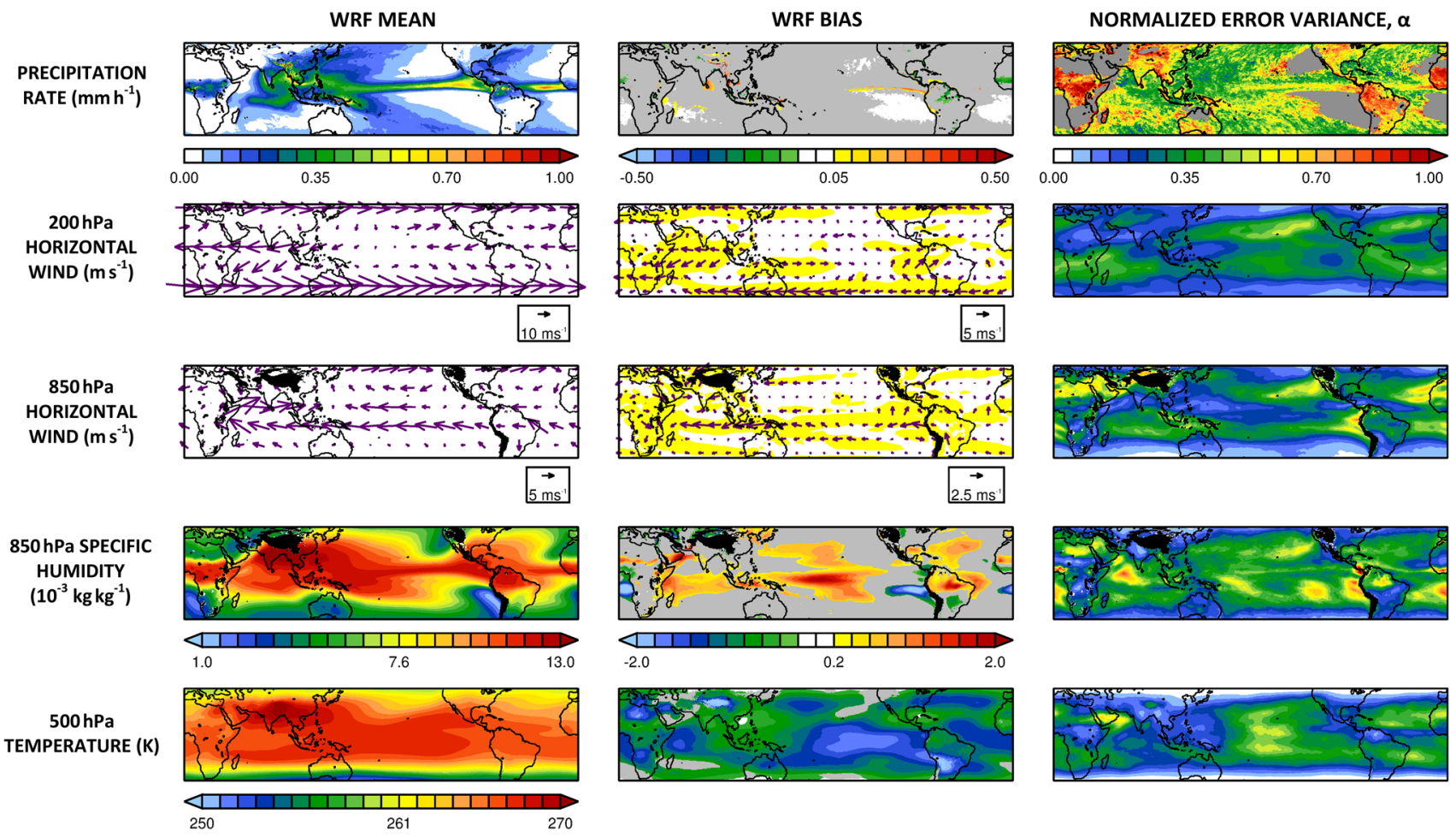

Fig. 2 Precipitation rate $\left(\mathrm{mm} \mathrm{h}^{-1}\right)$, horizontal wind vectors at 200 and $850 \mathrm{hPa}\left(\mathrm{m} \mathrm{s}^{-1}\right), 850 \mathrm{hPa}$ specific humidity $\left(10^{-3} \mathrm{~kg} \mathrm{~kg}^{-1}\right)$ and $500 \mathrm{hPa}$ temperature $(\mathrm{K})$ for the boreal summer monsoon season (JJAS). Left to right: WRF mean, bias (regions where $|\mu|<0.5$ are shaded in light grey; in the wind plots the yellow shading denotes regions where $|\mu|>0.5$ ) and pentad (5-day) normalized error variance $(\alpha)$. For the last diagnostic regions with very little precipitation (i.e. where the mean precipitation rate does not exceed $0.01 \mathrm{~mm} \mathrm{~h}^{-1}$ ) are shaded in dark grey. The colour bars are all linear with only a few of the values shown for clarity purposes. All panels in a given column use the same colour bar as the top row unless a different colour bar is otherwise provided. The $850 \mathrm{hPa}$ specific humidity and $500 \mathrm{hPa}$ temperature biases use the same colour bar despite the different units 


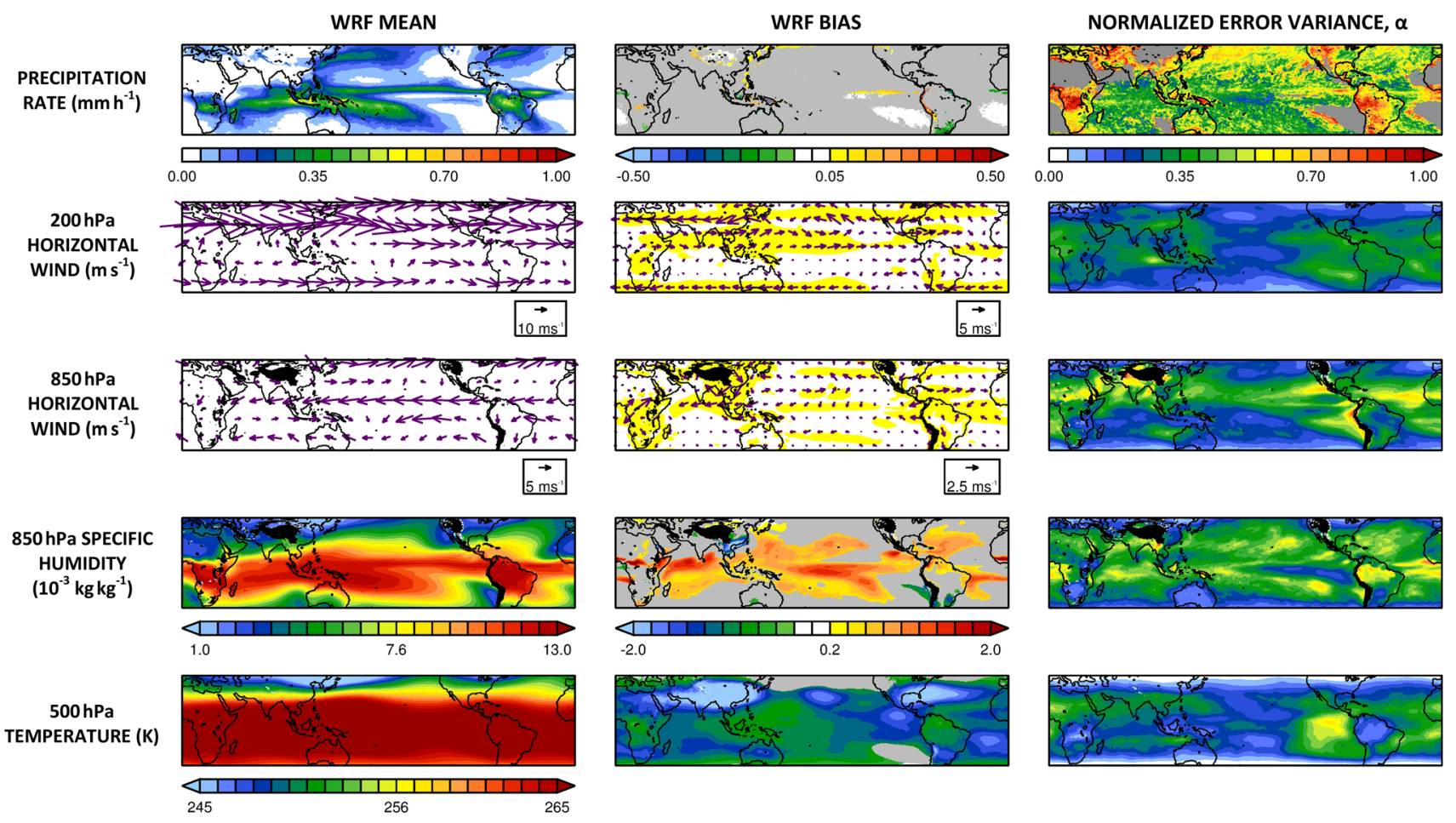

Fig. 3 As Fig. 2 but for the boreal winter monsoon season (DJFM)

bias at $850 \mathrm{hPa}$ blows from the ocean bringing in the more moist marine air into the Amazon basin. But precipitation is determined less by the mean low-level moisture (as evidently, it does not rain all the time) but more by the moisture fluctuation so that low-level moisture bias is not dynamically well-related to the precipitation bias.

For precipitation rate the other two diagnostics show good performance as the correlation is relatively high $(\sim 0.7$ to 0.8$)$ and the normalized error variance relatively low $(\sim 0.2$ to 0.3$)$. Exceptions are regions with light and irregular amounts of precipitation such as the eastern side of sub-tropical Pacific and Atlantic Oceans and deserts in northern and southern Africa and Arabian Peninsula, Tibetan plateau and Australia. This good performance is mainly a result of the modifications made to the cumulus scheme (Fonseca et al. 2015). The model biases are significant mainly over the high terrain (in particular in the Himalayas, Andes and in the mountains of Borneo, New Guinea and Sumatra) where a substantial fraction of the rainfall is produced by the microphysics scheme (not shown). In these regions WRF is known to overestimate the observed rainfall, as discussed in Teo et al. (2011), and an accurate simulation of the mountain precipitation also requires higher spatial resolution to properly resolve the orographic slopes. As the water vapour is a powerful greenhouse gas, regions with increased lower tropospheric moisture will experience an increased upward long-wave radiative flux leaving into space leading to colder temperatures at $500 \mathrm{hPa}^{-1}$.

The model is also found to overestimate the strength of the Asian monsoon wind in the two main seasons with the biases being significant at both low and upper-levels. The subtropical jet is weaker than that of CFSR in both hemispheres and all seasons. It is important to note that the magnitude of the wind bias is typically about a fourth (or less) of the magnitude of the mean wind at upper-levels and a third (or less) at low levels meaning that the model still captures relatively well the observed large-scale circulation even though interior nudging is not applied to the horizontal wind components at these two levels. For the horizontal winds, specific humidity and temperature, the other verification diagnostics, namely correlation $\rho$ and normalized error variance $\alpha$, are rather good indicating a good model performance despite the fact that in some regions the biases are significant.

We proceed to assess how well the model captures the seasonality of rainfall next. In Fig. 4 the top panels show the indicators $S, C$ and $n^{\prime}$ for WRF and TRMM for the 13-year period 1998-2010 as well as the difference between the two. The model captures well the observed precipitation seasonality with higher $S$ values in regions with light and irregular amounts of precipitation (such as the Sahara desert and the eastern side of the subtropical Atlantic and Pacific Oceans) and lower values in the deep tropics (as well as in some 


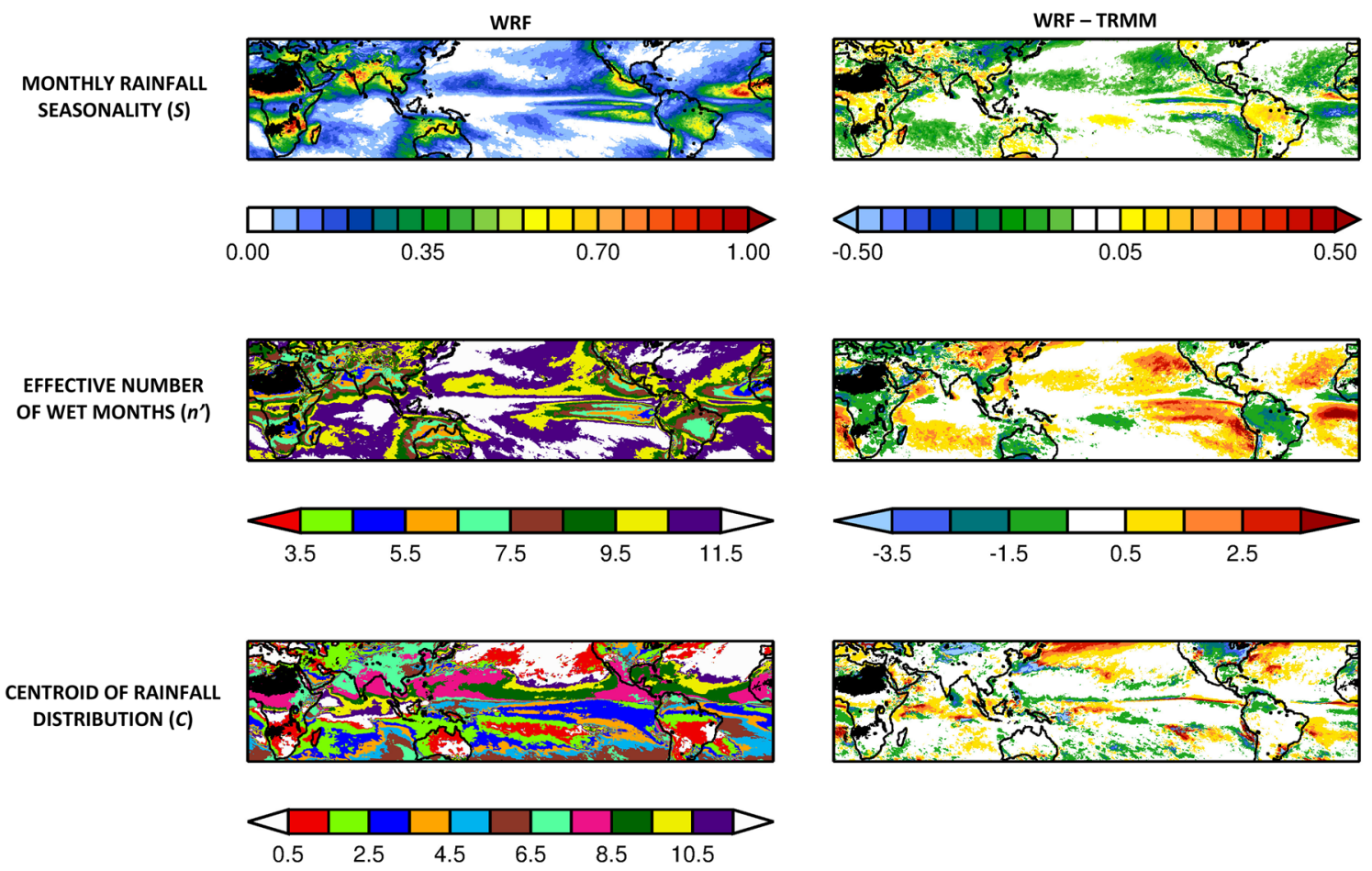

Fig. 4 Monthly rainfall seasonality $(S)$, effective number of wet months $\left(n^{\prime}\right)$ and centroid of rainfall distribution $(C)$ for WRF and the difference between WRF and TRMM for the period January 1998-

mid-latitude regions such as the eastern section of the US) where the precipitation is close to being uniformly distributed throughout the year. The difference between the two indicates that the model tends to overestimate the seasonality index over most land regions (i.e. in WRF over land the precipitation is more concentrated in the wet season) whereas over the oceans and northeast Asia the model's rainfall distribution tends to be more uniformly distributed than that observed. These biases are also present in $n^{\prime}$ with generally positive values over the oceans and negative values over land. It is interesting to note that the model captures very well the centroid of the precipitation distribution with the wettest month being either July or August (January or February) for monsoon regions in the Northern (Southern) Hemisphere. Over land $S$ errors are generally less than $0.1, C$ errors are typically less than one month and $n^{\prime}$ errors are about one month indicating a good model performance. The main exceptions are northeast Asia and northern South America where the verification diagnostics shown in Figs. 2 and 3 are not as good. However, even in this region the referred errors are still small. By and large the results presented in Figs. 2, 3 and 4 show that WRF not only captures well the magnitude of the observed rainfall but also its seasonality.

The focus of the model evaluation has so far been on the precipitation, large-scale circulation, low-level specific
December 2010. Regions where there is no rainfall in WRF/TRMM (i.e. where the mean precipitation rate does not exceed $0.01 \mathrm{~mm} \mathrm{~h}^{-1}$ ) are shaded in black. The conventions are as in Fig. 2

humidity and mid-tropospheric temperature but it also of interest to assess how well the model simulates surface fields such as the radiation fluxes, 2-m temperature and soil moisture. The verification diagnostics for these are shown in Fig. 5. As before, the evaluation is performed over the common period when the model and the observed/re-analysis dataset overlap: April 1988-December 2011 for NOCSv2, April 1988-March 2015 for CFSR and GHCN + CAMS, and April 2003-March 2013 for the ESA CCI soil moisture (excluding the pre-2003 data for which the uncertainty is high). The NOCSv2 and ESA CCI datasets included estimates of their uncertainity and so regions where the uncertainity is large were masked out in grey in Fig. 5 as explained in Appendix 2. The evaluation is performed using monthly data except for the soil moisture and surface fluxes over land for which pentad data is used as the datasets against which the WRF performance is verified are available on a higher temporal frequency (daily and 6-h, respectively).

Regarding the surface radiation fluxes, over the oceans they are compared with those given by NOCSv2 while over land the comparison is with CFSR as the model used to produce the re-analysis dataset uses the same land surface model as the one used in WRF. Over the oceans there are generally negative (slightly positive) biases in the net downward short-wave (long-wave) radiation flux. While these biases are consistent with the moist biases in much of 


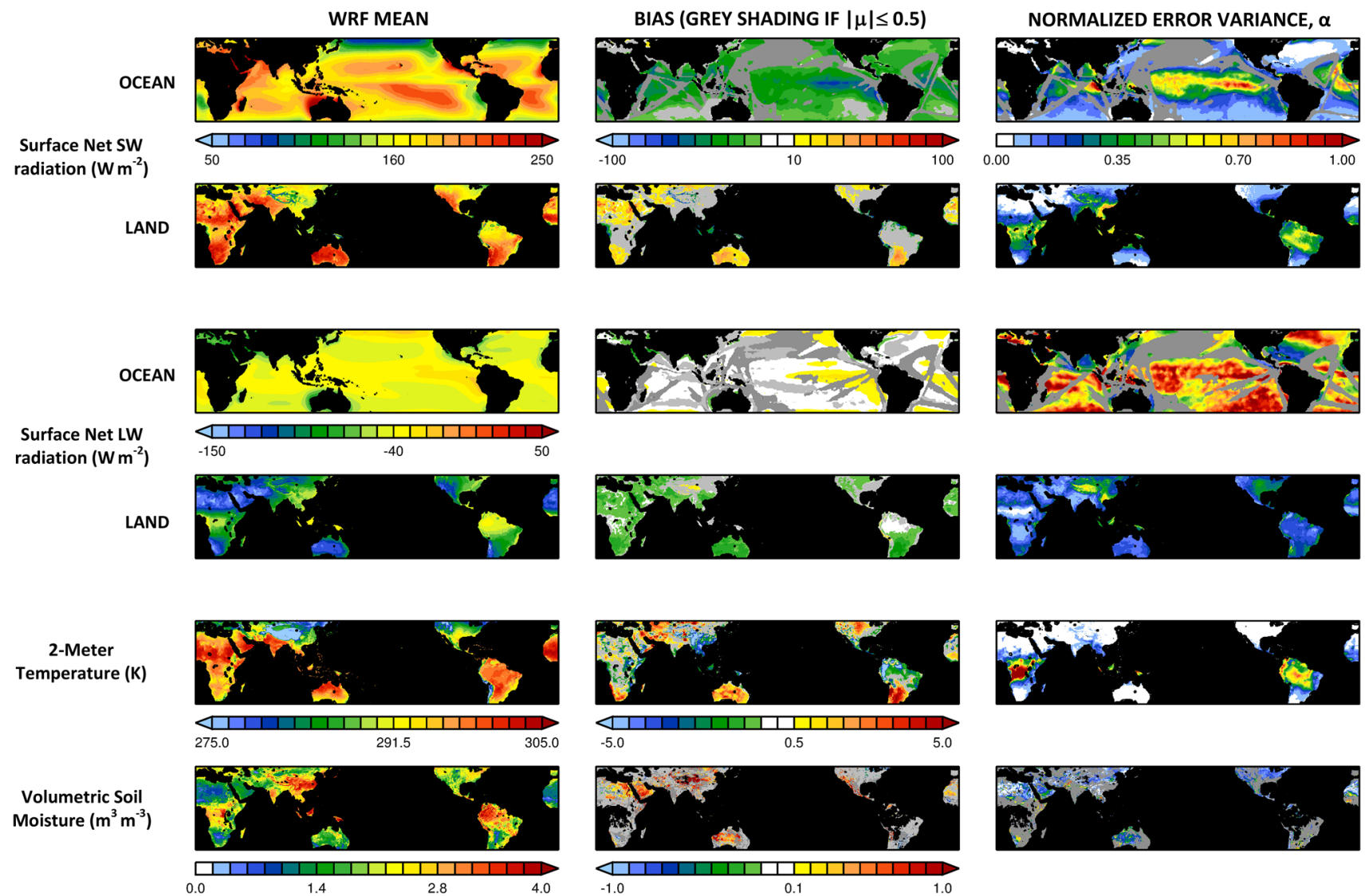

Fig. 5 Verification diagnostics for the surface net short-wave and long-wave radiation fluxes (positive downwards, $\mathrm{W} \mathrm{m}^{-2}$ ), 2-m temperature (K) and volumetric soil moisture $\left(\mathrm{m}^{3} \mathrm{~m}^{-3}\right)$. Left to right: WRF mean, bias (regions where $|\mu| \leq 0.5$ are shaded in light grey) and normalized error variance $(\alpha)$. The diagnostics are computed using monthly data except for soil moisture and surface fluxes over

the tropics, as shown in Figs. 2, 3 and 4, we highlight that they are the opposite of those shown in Koh and Fonseca (2016). This discrepancy stems from the different microphysics schemes used: here the GSFC microphysics scheme is used here whereas in Koh and Fonseca (2016) the WRF Double-Moment five-class microphysics scheme (WDM5; Lim and Hong 2010) is employed. Over the oceans, the WDM5 scheme is found perform well in particular in the equatorial tropics but underestimates the low-level cloud cover mainly in the eastern side of the subtropical oceans (Koh and Fonseca 2016), whereas the GSFC scheme produces more stratiform clouds which drastically cut down the downward short-wave radiation benefiting the subtropics while over-compensating the tropics (Fig. 5). However, the performance lost in the short-wave radiation field is gained by the near-zero bias in the long-wave radiation field, especially in the Indian Ocean, West Pacific and the regional seas of the Maritime Continent and the Carribean. The reason is with reduced surface downward short-wave radiation, land for which pentad data is used. In all diagnostics with respect to the NOCSv2 and ESA CCI soil moisture datasets regions where the uncertainty in the observations is large (see Appendix 2 for more details) are masked out in dark grey. For the volumetric soil moisture regions where observational data is missing are masked out in black. The conventions are as in Fig. 2

the SSKT is cooler and the sea surface radiates less in the long-wave spectrum when GFSC is used instead of WDM5. Incidentally, an interactive SSKT is essential for capturing this mechanism of indirect cloud-radiation interaction over the oceans.

A small bias in surface long-wave radiation indicates clearly a small bias in SSKT because of the simple relation between SSKT and surface long-wave emission. This implies better mean sensible heat flux and mean evaporative flux over the oceans. Not surprisingly, with the GSFC scheme, the mean nudging tendency on the midtropospheric water vapour mixing ratio is reduced in some regions, like the Pacific Inter-Tropical Convergence Zone (ITCZ), improving the dynamical consistency of the model simulation (not shown). However, even with the GSFC scheme, a large normalized error variance still exists in the surface radiative fluxes over the tropical oceans. The large error variance in surface long-wave radiation implies a large error variance in SSKT. As the increase 
of evaporative flux with temperature steepens with higher temperature, even if the SSKT bias is zero, a net positive bias in surface evaporation is expected from the large SSKT variance, explaining the excessive moisture source in the model. The consequent positive bias in tropospheric humidity further worsens the negative bias in surface downward short-wave radiation as water vapour is the main absorber of short-wave radiation in the troposphere.

Over land the biases in radiation fluxes indicate insufficient cloud cover in particular over southern South America, Australia and parts of northern Africa whereas in Southeast Asia the negative biases in short-wave radiation flux suggest too much cloud. Regarding the other verification diagnostics, they show good scores for the surface short- and long-wave radiation fluxes but not over the oceans in the tropics and southern hemisphere where the correlation $\rho$ is lower and, as a result, the normalized error variance $\alpha$ is higher. In fact, in some areas, $\alpha$ approaches the value of 1 which is the quality of a random forecast based on climatological variability. This attests to the general difficulty of getting month-to-month variations in cloud cover correct at grid-point resolution in the tropics.

Consistent with the biases in the surface radiation fluxes, the model overestimates the 2-m temperature over central parts of South America and Australia and underestimates it in the tropics in particular over southern China. It is important to stress that the GHCN + CAMS dataset used to evaluate the 2-m temperature is obtained by combining two individual datasets of station observations and using interpolation methods to produce a global dataset on a $0.5^{\circ} \times 0.5^{\circ}$ grid. Given that the surface topography, interpolated from a $0.08333^{\circ} \times 0.08333^{\circ}$ dataset, is not well captured at this grid spacing and the lack of observations in regions of high terrain, care should be taken when looking at the skill scores in these regions. The other diagnostics show a very good performance with $\rho$ close to 1 and $\alpha$ close to 0 except in the deep tropics as is consistent with the case for the surface radiation fluxes.

The final surface field to be evaluated is the soil moisture. This field is recognised by the World Meteorological Organisation (WMO) as an Essential Climate Variable (ECV) and is known to be important for the simulation of Intra-seasonal Oscillations (ISOs), a focus of this work, as over land ISOs are facilitated by land-atmosphere feedbacks (Saha et al. 2012). As the ESA CCI soil moisture data is available on a daily basis, the diagnostics are computed using pentad data. Although the uncertainty in the soil moisture observations is rather large, Fig. 5 shows that the WRF model does a good job in simulating this field with rather high $\rho$ and low $\alpha$. As far as the biases are concerned, WRF has a tendency to overestimate the soil moisture in a few specific areas which can be attributed to an overestimation of the surface precipitation or, as is the case in the desert regions, an underestimation of the surface evaporation (not shown).

\section{ENSO and IOD regression}

In this section the impact of ENSO and IOD on the climate of the global tropics $\left(20^{\circ} \mathrm{S}-30^{\circ} \mathrm{N}\right)$ is investigated. The ENSO and IOD indices used in this work are defined below, where a prime denotes the anomaly of the monthly mean from the same month's 27-year average climatology:

$$
\begin{aligned}
E N S O=S S T^{\prime}[ & \text { Niño } 3 \text { Modified Region }] \\
\text { ENSO }_{\text {MоDокI }}= & S S T^{\prime}[\text { Central Pacific }] \\
& -\frac{1}{2} S S T^{\prime}[\text { Eastern Pacific }] \\
& -\frac{1}{2} S S T^{\prime}[\text { Western Pacific }]
\end{aligned}
$$

$I O D=S S T^{\prime}[$ Western Indian Ocean $]-S S T^{\prime}[$ Eastern Indian Ocean $]$

where Niño 3 Modified Region $=\left[4^{\circ} \mathrm{S}-4^{\circ} \mathrm{N} ; 90^{\circ} \mathrm{W}-150^{\circ} \mathrm{W}\right]$; Central Pacific $=\left[10^{\circ} \mathrm{S}-10^{\circ} \mathrm{N} ; 165^{\circ} \mathrm{E}-140^{\circ} \mathrm{W}\right]$; Eastern Pacific $=\left[15^{\circ} \mathrm{S}-5^{\circ} \mathrm{N} ; 110^{\circ} \mathrm{W}-70^{\circ} \mathrm{W}\right]$; Western Pacific $=\left[10^{\circ} \mathrm{S}-20^{\circ} \mathrm{N} ; 125^{\circ} \mathrm{E}-145^{\circ} \mathrm{E}\right] ;$ Western Indian Ocean $=\left[10^{\circ} \mathrm{S}-10^{\circ} \mathrm{N} ; 50^{\circ} \mathrm{E}-70^{\circ} \mathrm{E}\right]$; Eastern Indian Ocean $=$ $\left[10^{\circ} \mathrm{S}-0^{\circ} ; 90^{\circ} \mathrm{E}-110^{\circ} \mathrm{E}\right]$.

In order to smooth out any intra-seasonal variability, a 5-month running mean is applied to all monthly SST anomalies before computing the above indices. The conventional ENSO and IOD indices are taken from Lestari and Koh (2016) while the ENSO Modoki index is taken from Weng et al. (2007). When studying WRF or CFSR outputs, the indices are computed using the CFSR SSTs which are also the prescribed ocean surface conditions in the WRF simulation, whereas when studying the observations, the indices are calculated using the SSTs from the HadISST1 dataset. The latter dataset is chosen as it is obtained mostly from in-situ observations and hence it is not contaminated with model data.

Conventional ENSO events are known to co-occur with IOD events, usually El Niño with IOD+ and La Niña with IOD- (Fischer et al. 2005). In order to assess the importance of the "unusual" co-occurrence of El Niño with IOD- and La Niña with IOD+, two combined indices, are defined:

$$
\begin{aligned}
& E I 1=E N S O \times|I O D| \\
& E I 2=|E N S O| \times I O D
\end{aligned}
$$

For the usual ENSO-IOD co-occurrences, both EI1 and EI2 give the same positive (El Niño with IOD+) or negative (La Niña with IOD-) value and so the difference, 
(EI1 - EI2), is identically zero. (EI1 - EI2) is non-zero only in the rare co-occurrence events: positive for El Niño with IOD-; negative for La Niña with IOD+. In practice, and as seen in Fig. 6a, (EI1-EI2) sometimes makes transient departures from zero when the ENSO or IOD index is weak, such as during ENSO or IOD neutral years and around the onset or termination of a co-occurrence event of the usual type. Likewise, the sum, (EI1+EI2), identifies the usual
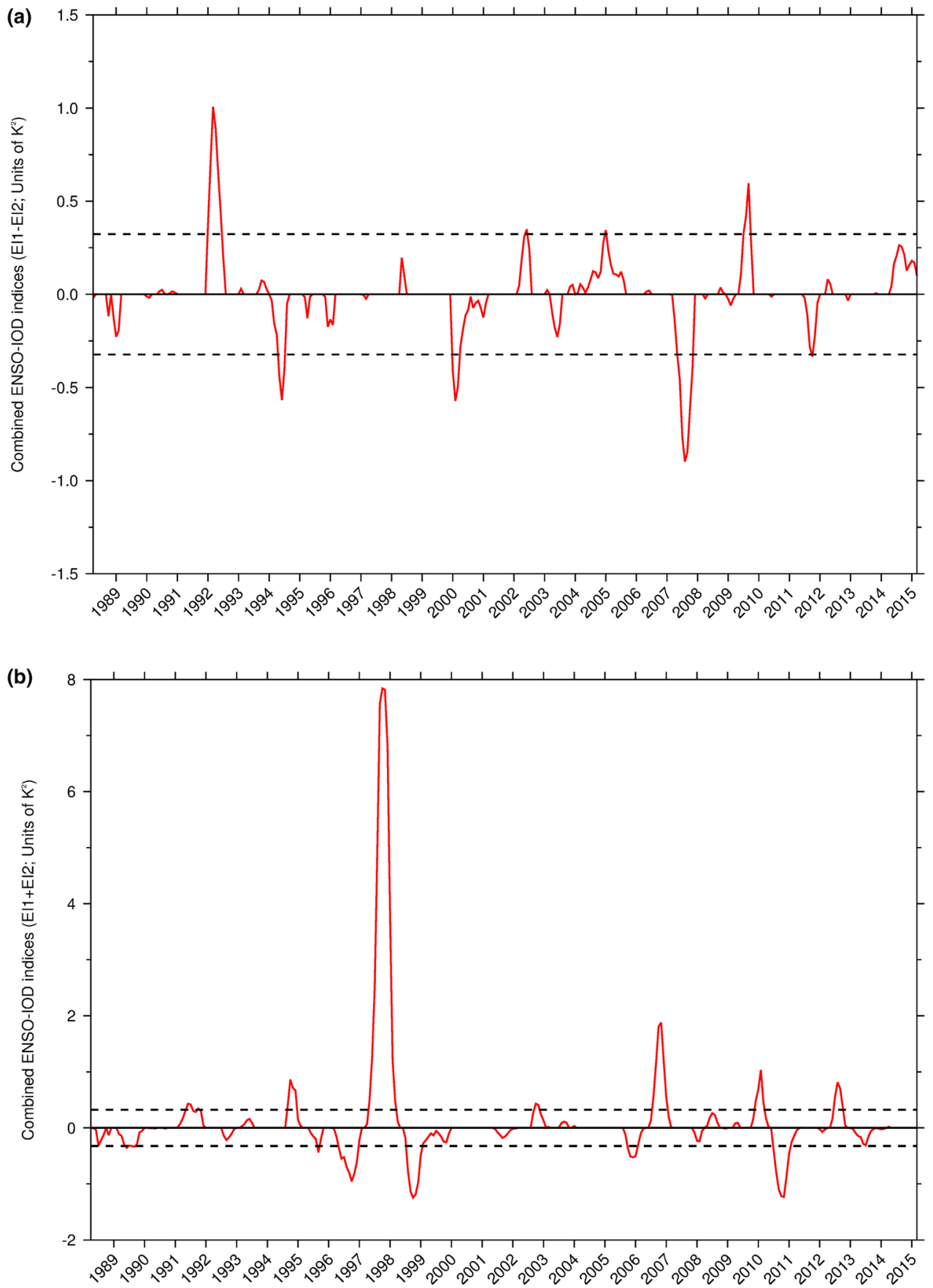

Fig. 6 Monthly a EI1 - EI2 and b EI1 + EI2 where EI1 and EI2 are the two combined ENSO-IOD indices defined in Eqs. (6) and (7), respectively, in the text. The dashed lines denote $\pm \sqrt{2} \sqrt{\mu_{|I O D|}^{2} \sigma_{|E N S O|}^{2}+\mu_{|E N S O|}^{2} \sigma_{|I O D|}^{2}+\sigma_{|E N S O|}^{2} \sigma_{|I O D|}^{2}}$ where $\mu_{X}$ and $\sigma_{X}^{2}$ are the mean and variance of $X$, respectively, the standard deviation of the index (EI1 - EI2) or (EI1 + EI2) assuming random co-occurrence of the signs of the ENSO and IOD indices. The notable excursions beyond the dashed lines show that those co-occurrences (whether in the unusual or usual combinations) may not be simply coincidental. The ENSO and IOD indices used to compute the combined indices shown above are obtained using WRF/CFSR SSTs 


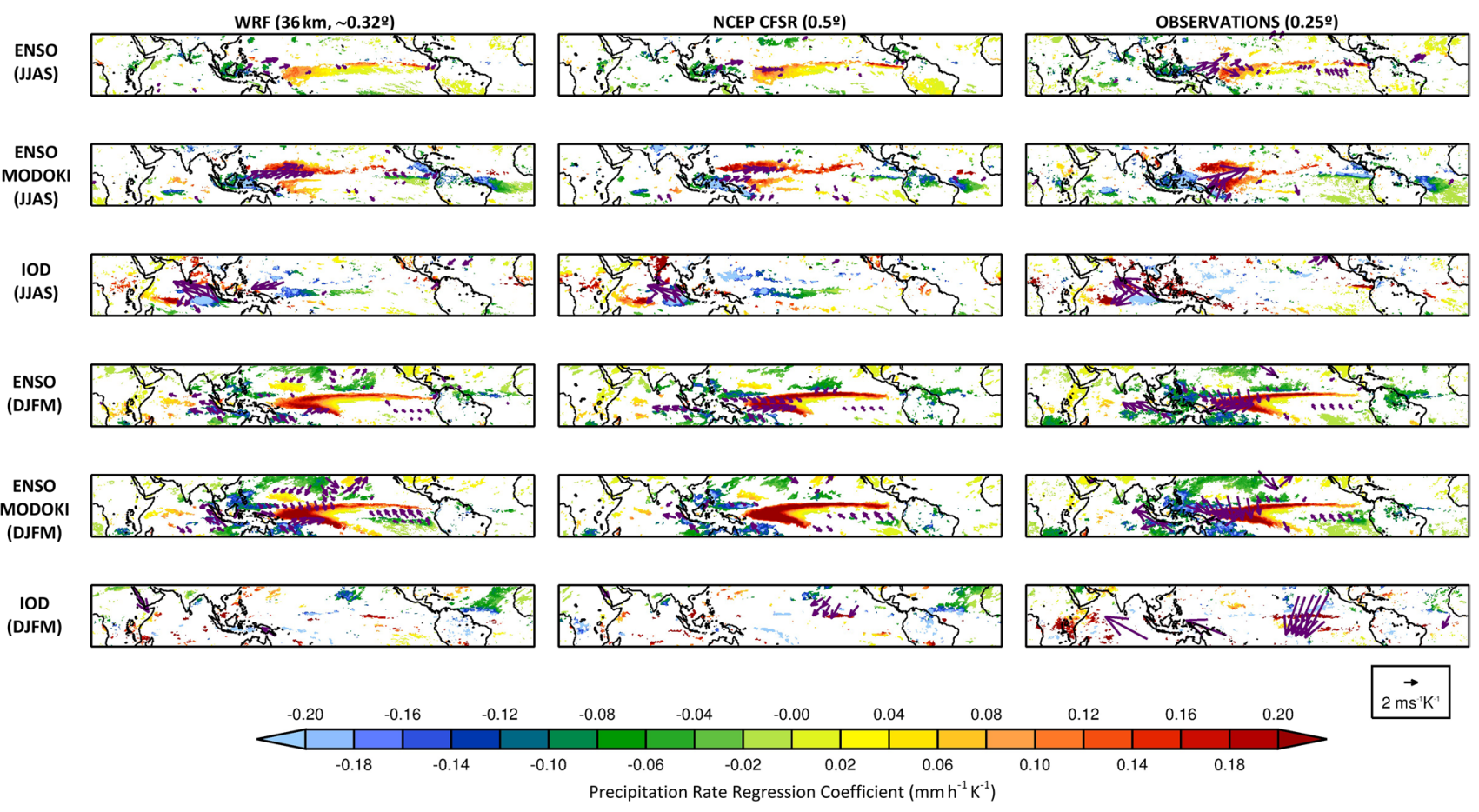

Fig. 7 Linear regression of precipitation rate (shading, $\mathrm{mm} \mathrm{h}^{-1}$ $\mathrm{K}^{-1}$ ) and 10-m horizontal wind vector (arrows, $\mathrm{m} \mathrm{s}^{-1} \mathrm{~K}^{-1}$ ) against the ENSO, ENSO Modoki and IOD indices for the boreal summer (JJAS) and winter (DJFM) monsoon seasons and for the period December 1999-September 2009. Shown are the regression coefficients (only those statistically significant at $90 \%$ level are plotted) for WRF, NCEP CFSR and observations (TRMM 3B43 for the precipitation rate and QuikScat for the 10-m winds) for the wider tropics $\left(20^{\circ} \mathrm{S}-30^{\circ} \mathrm{N}\right)$. For WRF, CFSR and observations only one arrow is displayed every 10-30 grid-points (if significant) for clarity. The conventions are as in Fig. 2

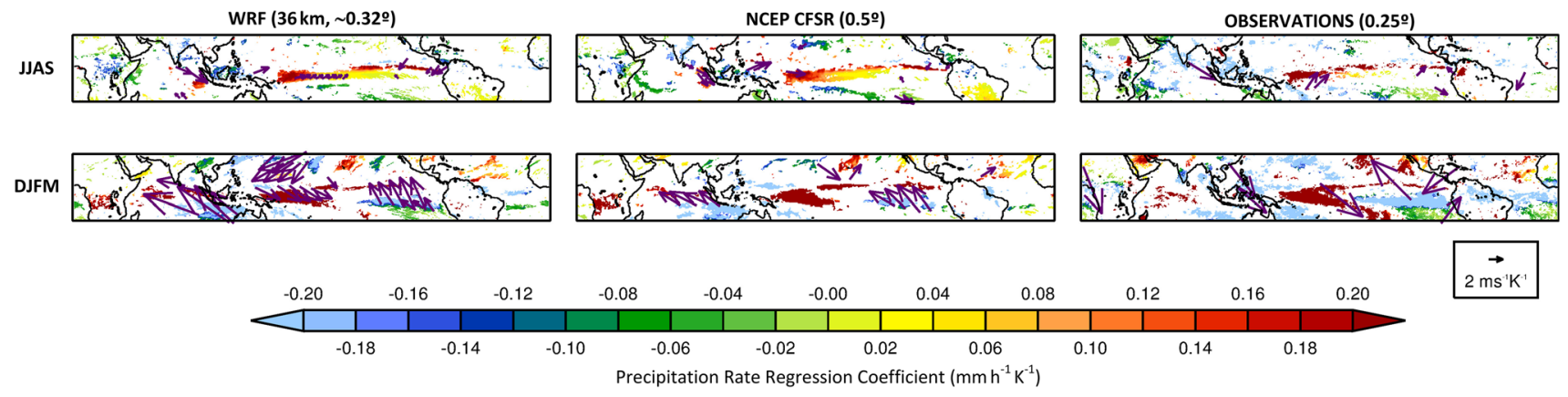

Fig. 8 As Fig. 7 but for a linear regression against the (EI1 - EI2) index where EI1 and EI2 are the two combined ENSO-IOD indices defined in Eqs. (6) and (7) in the text. Non-zero values of the index

co-occurrence of El Niño with IOD+ or La Niña with IOD- (cf. Fig. 6b) but as they are better known, we shall not study these cases.

The CFSR and WRF monthly mean precipitation rate and $10-\mathrm{m}$ horizontal wind vectors are linearly regressed against the monthly mean ENSO and IOD indices separately for the boreal summer (JJAS, 2000-2009) and winter (DJFM, 1999-2009) monsoon seasons. This 10-year period is chosen as it is the period in which the WRF, CFSR and flanked by zeros on both sides were excluded in the computation of the regression coefficient

observational data overlap. The regression coefficients for the global tropics $\left(20^{\circ} \mathrm{S}-30^{\circ} \mathrm{N}\right)$ are shown in Fig. 7. Also shown are the regression coefficients for observations with TRMM data used for precipitation rate and QuikSCAT data for the winds. In Fig. 8 the difference between the regression coefficients for the two combined ENSO-IOD indices, EI1 - EI2, is given. In all plots only regression coefficients significant at the $90 \%$ level are shown with the land-sea mask at the dataset's resolution (i.e. $36 \mathrm{~km}$ or $\sim 0.32^{\circ}$ for 
WRF, $0.5^{\circ}$ for NCEP CFSR and $0.25^{\circ}$ for both TRMM and QuikSCAT) overlain.

In the boreal summer monsoon season, the largest impacts of conventional El Niño events are over Southeast Asia (mostly drying tendency, a well-known feature of the ENSO response; Xie et al. 2009) and the Central and Eastern equatorial Pacific (general increase in precipitation). In line with the large-scale anomalous pattern (Weng et al. 2007), in El Niño Modoki events the increase in the precipitation in the Pacific Ocean is only present in parts of the western and central regions, on the eastern side and equatorial Atlantic there is a reduction of the rainfall. The drying over Southeast Asia is generally of a larger magnitude compared to conventional El Niño events. The IOD impacts are more localized than that of both ENSO types, confined mainly to the west and southwest of Sumatra and eastern Indian Ocean where there is a decrease in precipitation in IOD+ events. These tendencies, present in the observations and re-analysis, are well captured by WRF that is run without data assimilation and only with prescribed SSTs from CFSR and mid-tropospheric humidity-nudging to the re-analysis dataset effective on the timescale of the seasonal climatology.

In the boreal winter monsoon season both ENSO types have a larger and more widespread impact on the precipitation which is expected as ENSO events typically reach their largest amplitude in this season. In parts of the Central Pacific and the South Pacific Convergence Zone (SPCZ) the rain rate increase exceeds $0.20 \mathrm{~mm} \mathrm{~h}^{-1} \mathrm{~K}^{-1}$. The slight increment in precipitation over Mexico in El Niño events in this season is a result of an anomalous low-pressure system that is part of the Pacific North-American (PNA) pattern (Wallace and Gutzler 1981). The drying tendency over Southeast Asia is generally stronger and more widespread in Modoki events. IOD has a rather small impact in the wider tropics in DJFM with only a hint of a tendency for increased precipitation over parts of eastern Africa and decrease in precipitation over the western tropical Atlantic. Overall both WRF and CFSR capture well the observed regression coefficients although the model and the re-analysis are more similar between themselves than with the observations. This is because the regional atmospheric impacts are mainly SSTdriven and WRF uses the prescribed SST of CFSR.

In order to assess the importance of the "unusual" co-occurrence of ENSO and IOD events (i.e. El Niño events occurring with IOD- events and La Niña with IOD+events), in Fig. 8 the regression coefficients against the index (EI1 - EI2) is shown. As stated before, for the usual co-occurrences the two indices are identical and so this difference should be identically zero. Hence non-zero values correspond to the impacts due to "unusual" co-occurrence of these two modes. For both seasons, and bearing in mind that positive (EI1 - EI2) means [El Niño, IOD-] paired conditions and vice-versa, a comparison of the regression coefficients in Figs. 7 and 8 reveals that the ENSO impacts manifest themselves nearly everywhere in the three datasets. There are a few exceptions: e.g. to the south-west and west of Sumatra in WRF and CFSR and over north-western South America in the observations in JJAS, as well as over the tropical eastern North Atlantic in DJFM where the IOD impacts manifest themselves. By and large WRF and CFSR capture well the observed regression coefficients for both seasons over the oceans but not so well on land. It is important to stress that even though the amplitude of the regression coefficients in Fig. 8 is generally comparable to, or larger than, that obtained in the regression against the individual indices in Fig. 7, the amplitude of the EI1 - EI2 combined index is generally smaller, typically less than 0.5 as seen in Fig. 6, meaning that the overall impact of the "unusual" co-occurrence of ENSO and IOD will not be as significant.

Generally speaking, WRF and CFSR have comparable regression coefficients with tropical inter-annual variations that are similar to those observed. Now, CFSR is a re-analysis dataset obtained using a coupled atmosphere-ocean system into which observations are assimilated, whereas WRF is an atmosphere-only model used to downscale CFSR data without additional regional data assimilation. This suggests that in the tropics today, where there is low (temporal, horizontal and/or vertical) density in quality observational data, having regional data assimilation on the pentad to sub-seasonal timescale may not be necessary for the regional model to better capture the atmospheric state, especially in variables for which no data is assimilated directly, e.g. rainfall. Performing regional downscaling to higher resolution using good boundary conditions from global datasets (in which data has already been assimilated globally) has its advantages because at least the mesoscale dynamics and local circulations are better represented. In fact, WRF has smaller biases than CFSR for rainfall in the Pacific ITCZ and Congo basin (cf. supplementary material). This result has important implications for the present allocation of effort and resources for tropical atmospheric modelling and research.

\section{MJO and BSISO-interaction with ENSO and IOD}

In this section the focus is on the MJO and BSISO and how they interact with ENSO and IOD. For the MJO, the daily mean WRF data is projected onto the Real-time Multivariate MJO (RMM) empirical orthogonal functions (EOFs) defined in Wheeler and Hendon (2004) for both the boreal summer and winter monsoon seasons. For the BSISO, the daily mean WRF output data is projected onto the BSISO EOFs defined in Lee et al. (2013) for the extended boreal summer monsoon season (May to October, MJJASO). A 5-day running mean 

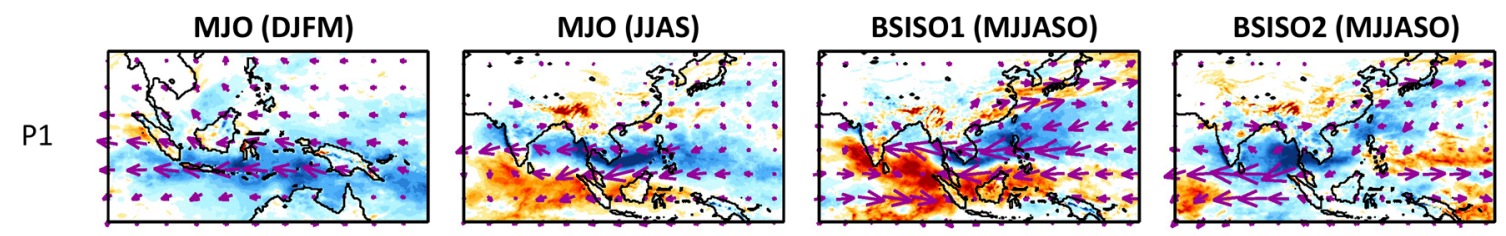

P2
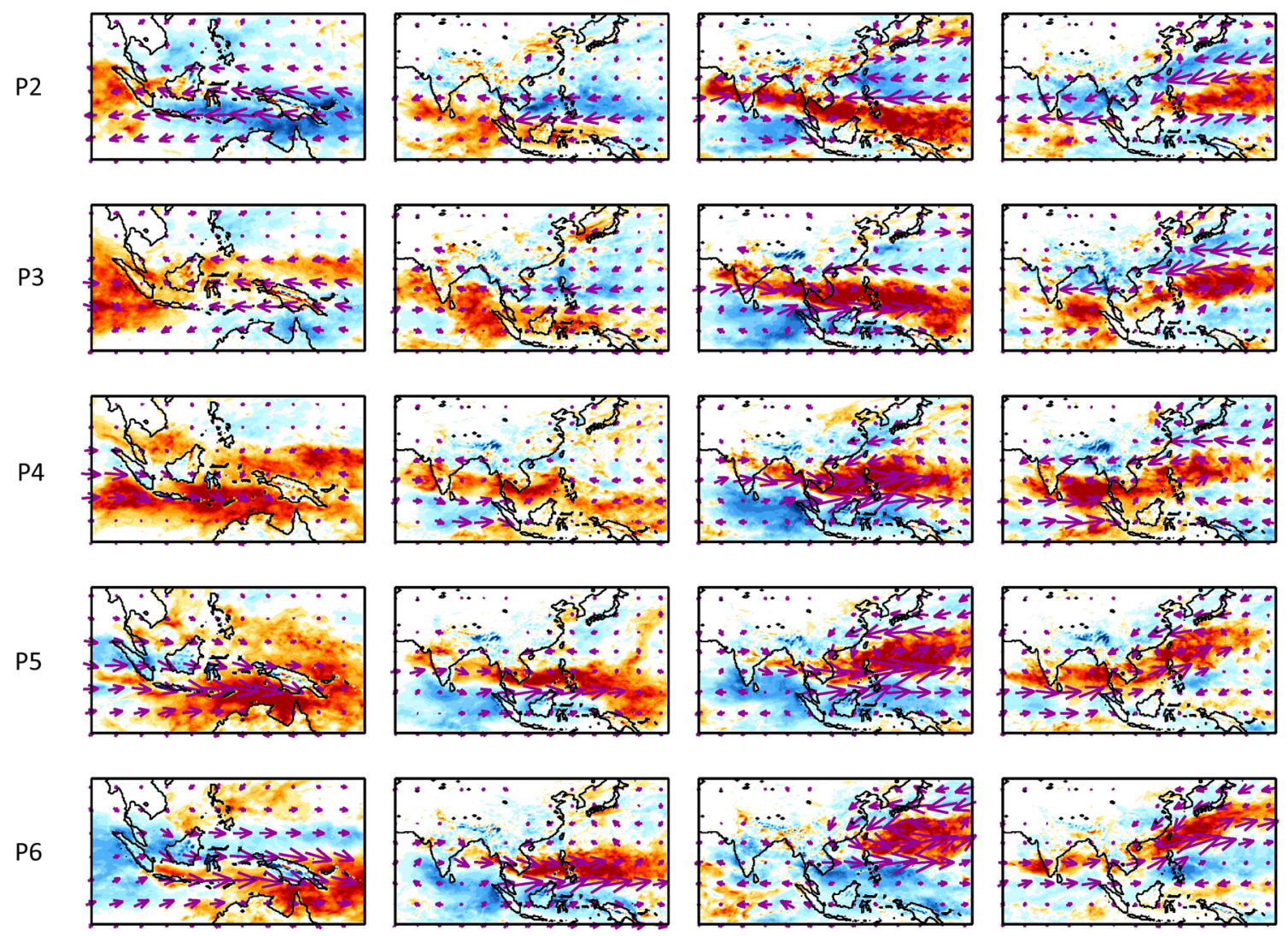

P7
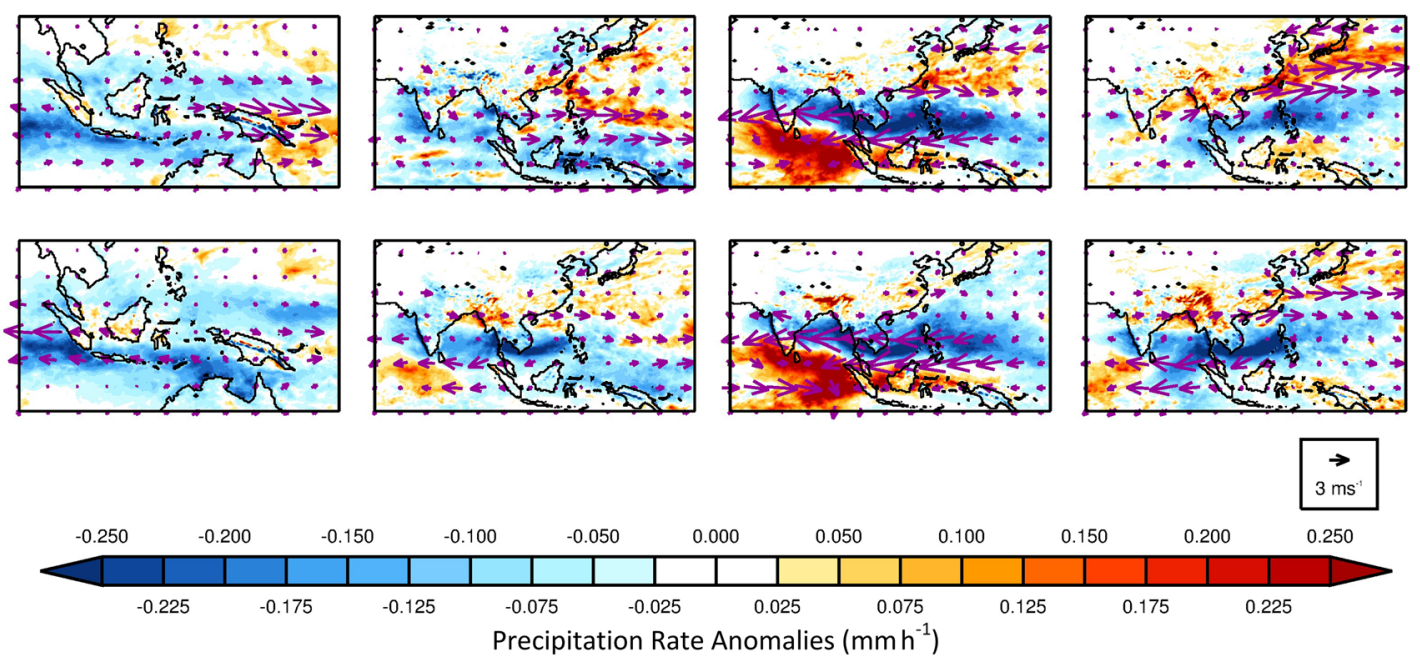

Fig. 9 The life cycle composite of precipitation rate (shading, mm $\mathrm{h}^{-1}$ ) and $850 \mathrm{hPa}$ horizontal wind vector (arrows, $\mathrm{m} \mathrm{s}^{-1}$ ) anomalies for the different phases of the MJO and BSISO for the period 1st April 1988-31st March 2015. Days of weak RMM or BSISO1/2 indices (i.e. index amplitude less than 1) are taken out before mak- ing the composites. The fields are shown for East Asia $\left(10^{\circ} \mathrm{S}-46^{\circ} \mathrm{N}\right.$, $90^{\circ} \mathrm{E}-160^{\circ} \mathrm{E}$ ) in the boreal summer monsoon season (JJAS for MJO and MJJASO for BSIO1 and BSISO2) and Southeast Asia $\left(20^{\circ} \mathrm{S}-20^{\circ} \mathrm{N}, 90^{\circ} \mathrm{E}-160^{\circ} \mathrm{E}\right)$ in the boreal winter monsoon season (DJFM). The conventions are as in Fig. 2 
is applied to the RMM and to the BSISO indices 1 and 2 (BSISO1 and BSISO2) thus obtained to remove synoptic perturbations. Figure 9 shows the life-cycle composite of precipitation rate and $850 \mathrm{hPa}$ horizontal wind anomalies for the eight phases of the MJO and BSISO indices 1 and 2 for the Maritime Continent and the wider Asian continent in the boreal winter and summer respectively where the intraseasonal variability is especially strong from 1st Apr 1988 to 31st Mar 2015 (the composites for the global tropics are shown in Figure S10).

\subsection{Evidence of successful ISO downscaling}

An inspection of Figs. S10 and 9 reveals that WRF simulates well the MJO and the BSISO. In the boreal summer, Fig. 9, northward propagation is observed with the region of intense rainfall moving from the equatorial Indian Ocean and Sunda Shelf in phase 1 to India, Bay of Bengal, South China Sea and Philippine Sea in phases 3-6. In the boreal winter such northward propagation dies down by phase 6 ; there is a strong eastward propagation across the Maritime Continent with the largest amplitudes in the Timor, Banda and Arafura Seas as well as in the Gulf of Carpentaria and Melanesia. Within the large-scale envelopes of active and suppressed convection, pockets of the precipitation anomaly sometimes have the opposite sign such as in parts of Borneo in phase 8 and New Guinea in phase 1 in DJFM. This feature evidenced in observations is sometimes described as the MJO signal "leaping ahead" of the main MJO envelope (Peatman et al. 2014). The good performance of WRF here is reflective of the importance of having the right meanstate water vapour distribution, as highlighted by Ulate et al. (2015), and of accounting for the high-frequency variability in the SSTs, as noted in Stan (2017), through the use of the SSTs from CFSR.

A comparison of Fig. 9 with the composites given in Lee et al. (2013) shows that the model also captures the BSISO1 and BSISO2 reasonably well. BSISO1 shows mainly a northward propagation across southern and eastern Asia and is stronger than that observed for the boreal summer MJO. BSISO2 shows a northward or northwestward propagation over Asia. As pointed out in Lee et al. (2013) and Moon et al. (2012), despite the fact that the EOFs used to define the BSISO indices are restricted to the Asian monsoon region, there are associated signals in the East Pacific and North American monsoon regions (Figure S10).

While the strong correlation of BSISO1 with RMM in the boreal summer has been noted by Lee et al. (2013), our regional and global tropical composites show that both BSISO1 and BSISO2 can show strong similarities to RMM, e.g. between phases 1 of BSISO1 and RMM, and phases 8 of BSISO2 and RMM. Thus it is an over-simplification to identify BSISO1 as a regional manifestation of boreal summer RMM. The truth is more likely that the (BSISO1, BSISO2)-pair and the RMM are different but related EOFcharacterizations of boreal summer ISO in the global tropics. After all, EOF analyses are empirical techniques and should not be mistaken as the fundamental principles for equating or distinguishing dynamical phenomena.

\subsection{Cross-scale interaction between ISOs and ENSO/ IOD}

Having verified that WRF simulates well the MJO and BSISO above and captures the impacts of the IOD and both types of ENSO earlier, the interaction between the intra-seasonal and inter-annual modes of variability can then be reliably analyzed from the model outputs over all 27 years of simulation. First, analogous daily ENSO and IOD indices were computed using Eqs. (3)-(5), where daily mean SST and daily climatology substitute their monthly counterparts before applying a 150-day running average on the daily anomalies. The amplitude of the MJO or BSISO index as well as the anomalies of daily mean rainfall rate and $850 \mathrm{hPa}$ horizontal wind from the daily climatology at every grid point, are linearly regressed against the daily ENSO and IOD indices for each MJO or BSISO phase. For rainfall and wind, days of weak (or practically no) ISO activity, defined as when the ISO amplitude is less than 1 , are separately regressed as one group, different from the other days which are split among eight phases.

Figure 10 shows the linear regression intercept and coefficient of the ISO index amplitude with respect to the conventional ENSO, ENSO Modoki and IOD indices and the regressed ISO index amplitude for typical values of the ENSO and IOD indices $( \pm 1 \mathrm{~K}$ for ENSO and $\pm 0.5 \mathrm{~K}$ for IOD) for each MJO and BSISO phase. Regarding the MJO, the regression intercepts are larger in DJFM compared to JJAS implying stronger MJOs in boreal winter than summer during years neutral to ENSO or IOD, which is consistent with observations (Zhang and Dong 2004). For field significance at $90 \%$ confidence level, only MJO in JJAS and BSISO1 are influenced by all three modes of inter-annual variations and only IOD has influence on both modes of BSISO.

With reference to Fig. 10, conventional El Niño events lead to a slight weakening of the amplitude of the MJO phase 1 and a strengthening of that of phases 2-5 and 7-8 in JJAS The impact of conventional El Niño on the MJO amplitude is generally positive in JJAS but practically absent in DJFM. The analogous impact of El Niño Modoki seems to be generally positive as well but not as significant. The interaction with IOD is even less significant. As shown in Fig. 10, for all significant MJO regressions, the regressed change in MJO index amplitude for typical ENSO and IOD anomalies is 

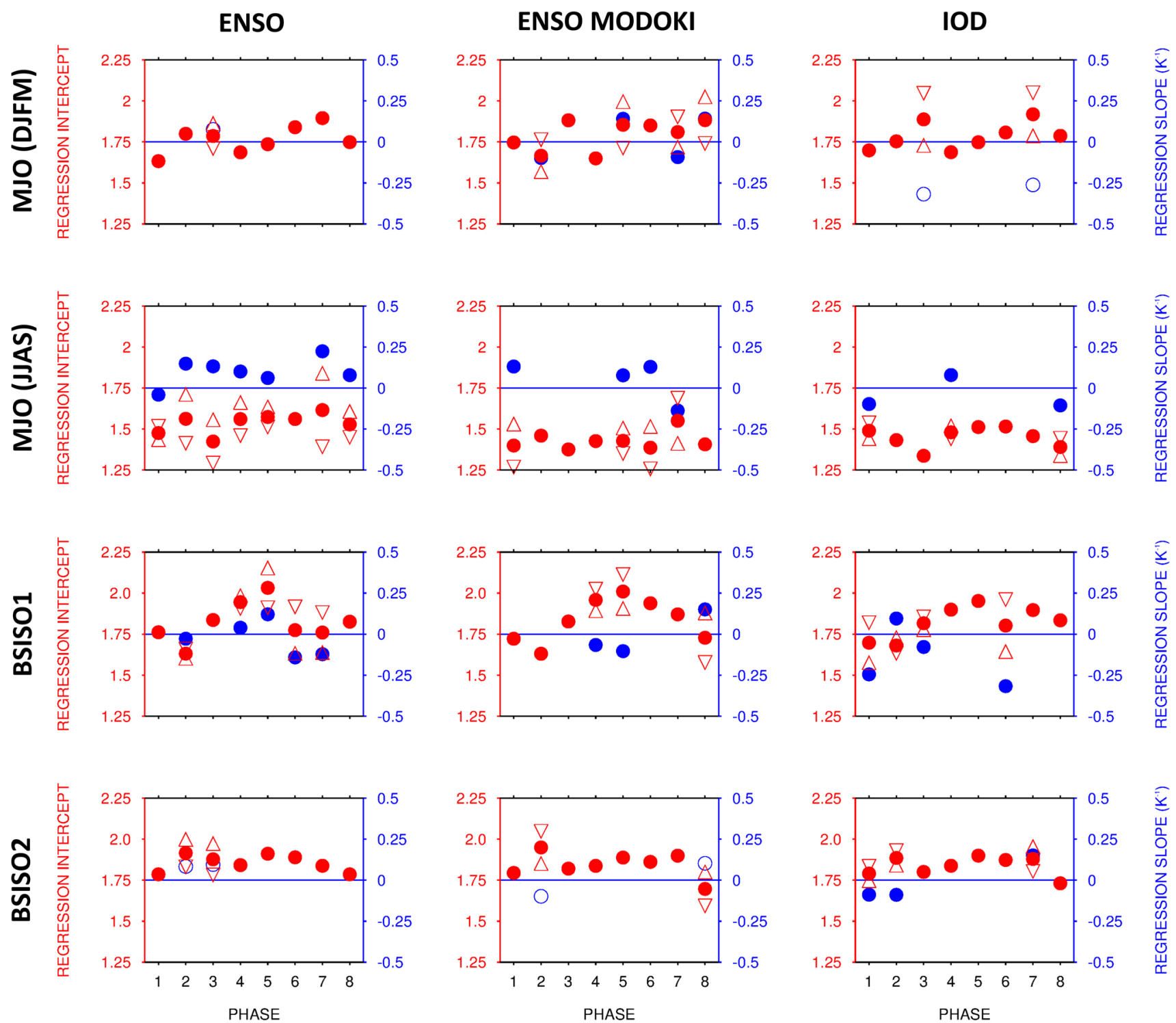

Fig. 10 Regression intercept (left axis, filled red circles) and coefficient (right axis, blue circles, $\mathrm{K}^{-1}$; only those statistically significant at $90 \%$ level are plotted; the circles are filled if the regression coefficients are statistically significant for 3 or more phases as in this case, and for the $90 \%$ confidence level, the probability that they are statistically significant due to chance is less than 10\%) of the ISO index

$10-20 \%$ of the regression intercept indicating that the variability in the MJO amplitude is small but non-negligible. It is important to stress that this does not mean that ENSO and IOD will not interact even more strongly with the MJO in some localised regions as the index is defined for the whole tropical belt $\left(15^{\circ} \mathrm{S}-15^{\circ} \mathrm{N}\right)$. As for BSISO, conventional El Niño and El Niño Modoki have opposite impact on the amplitude of phases 4 and 5 of BSISO1 when the rainfall is more intense across Indochina and the Philippines (Fig. 9), whereas BSISO2 seems to manifest significant influence by IOD and not by either type of ENSO. amplitude against the ENSO, ENSO Modoki and IOD indices and ISO amplitude considering a perturbation of $\pm 0.5 \mathrm{~K}$ for IOD and \pm $1 \mathrm{~K}$ for ENSO (left axis, upward/downward pointing triangles) for the period 1st April 1988-31st March 2015. Shown are the results for the 8 phases of the MJO (boreal summer and winter monsoon seasons), BSISO1 and BSISO2

The results for regressions of the grid-point anomalies of daily mean rainfall rate and $850 \mathrm{hPa}$ horizontal wind from the daily climatology are now presented. We show the regression intercepts and coefficients of MJO (for weak MJO, for which $\sqrt{R M M_{1}^{2}+R M M_{2}^{2}}<1$, as well as for each phase of strong MJO) with conventional ENSO for the boreal summer (JJAS) and winter (DJFM) seasons in Fig. 11 for MJO phases 2, 4, 6 and 8 (for all MJO phases in Figure S11) where only regression coefficients significant at the 95\% level are plotted. The regression intercepts for phases 
REGRESSION OF MJO (JJAS) AGAINST ENSO

REGRESSION INTERCEPT
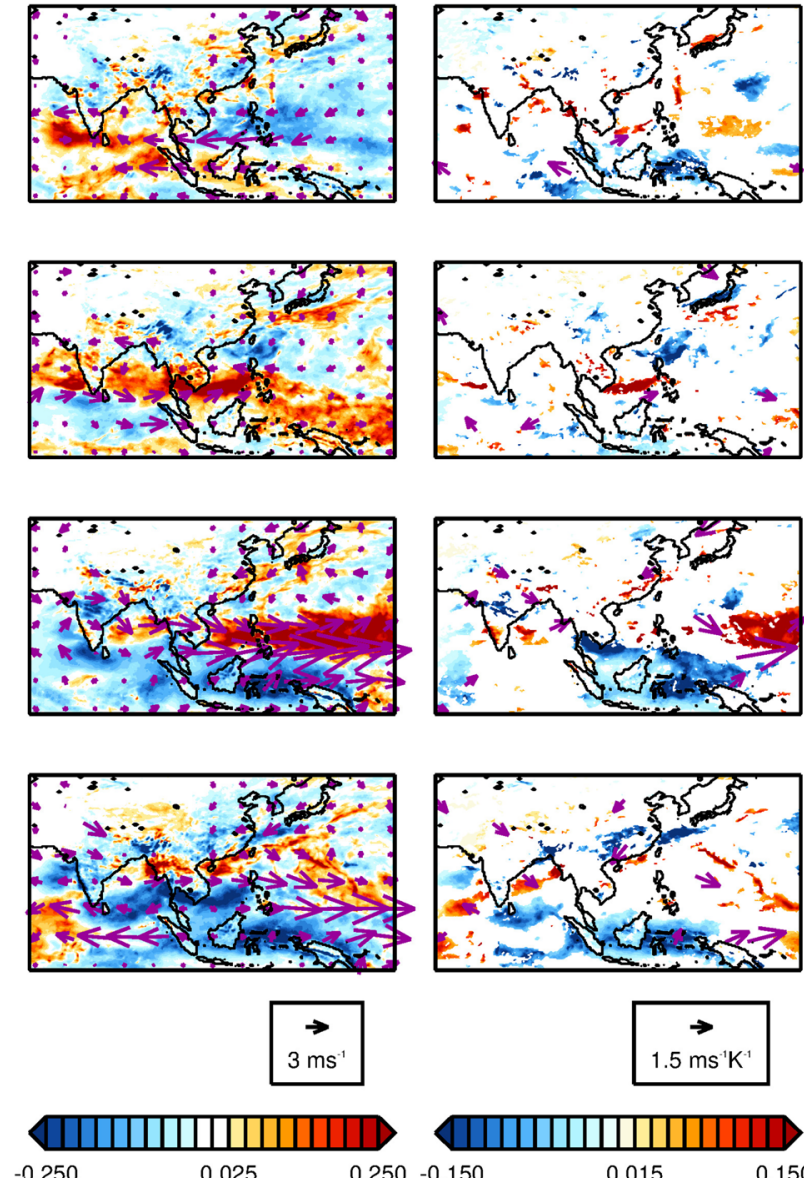

$-0250$

Regression Intercept $\left(\mathrm{mm} \mathrm{h}^{-1}\right)$

REGRESSION COEFFICIENT
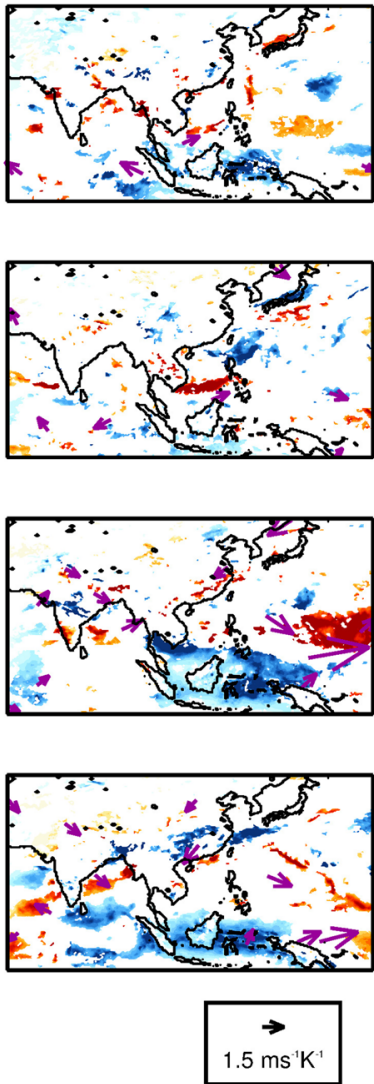

Regression Coefficient $\left(\mathrm{mm} \mathrm{h}^{-1} \mathrm{~K}^{-1}\right)$

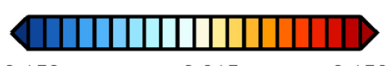

Fig. 11 Linear regression of precipitation rate and $850 \mathrm{hPa}$ horizontal wind vector anomalies with respect to the daily climatology of the boreal summer (left) and winter (right) MJO with the conventional ENSO index. The left panel shows the regression intercept $\left(\mathrm{mm} \mathrm{h}^{-1}\right.$ for the precipitation and $\mathrm{m} \mathrm{s}^{-1}$ for the winds) and the right

1-8 represent the MJO life-cycle under neutral ENSO conditions and are very similar to the all-ENSO-phase composite shown in Fig. 9 confirming the linearity of the interaction between the intra-seasonal and inter-annual variations assumed in our regression analysis. Positive regression coefficients (warm colours or eastward/northward vectors) simultaneously denote positive and negative anomalies of rainfall or zonal/meridional wind respectively during El Niño and La Niña, whereas negative regression coefficients (cool colours or westward/southward vectors) denote the converse. As this technique necessarily constrains the La Niña impacts to be always equal and opposite to the El Niño impacts, we need only discuss the latter. Under weak MJO activity, the regression coefficient represents ENSO are as in Fig. 2 influences are virtually absent.

REGRESSION OF MJO (DJFM) AGAINST ENSO
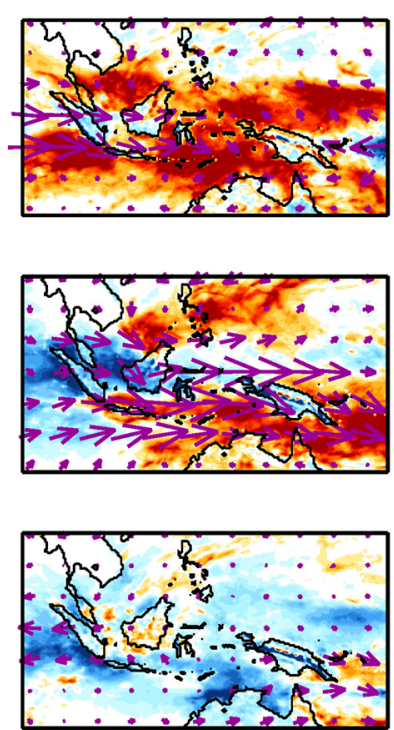

REGRESSION INTERCEPT
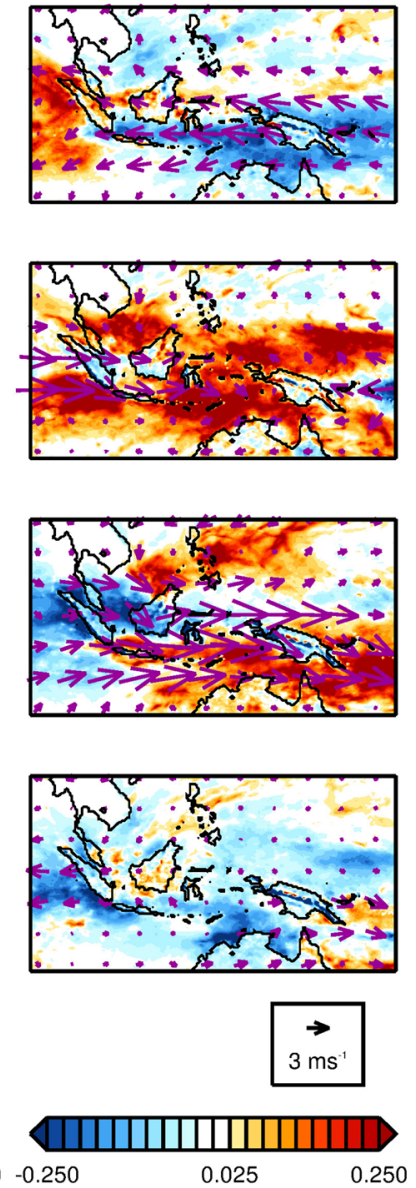

Regression Intercept $\left(\mathrm{mm} \mathrm{h}^{-1}\right)$
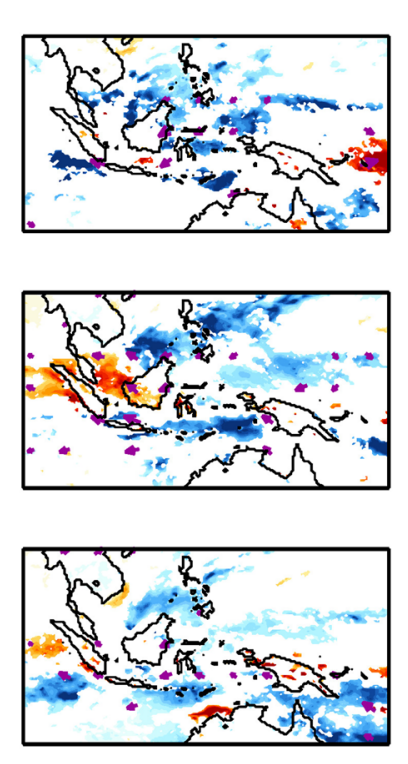

REGRESSION COEFFICIENT
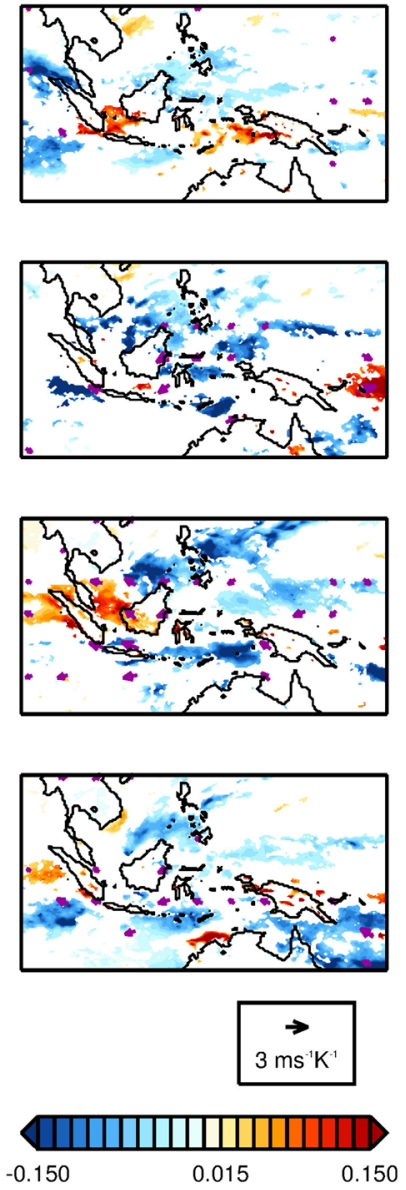

Regression Coefficient $\left(\mathrm{mm} \mathrm{h}^{-1} \mathrm{~K}^{-1}\right)$

panel shows the regression coefficient $\left(\mathrm{mm} \mathrm{h}^{-1} \mathrm{~K}^{-1}\right.$ for the precipitation and $\mathrm{m} \mathrm{s}^{-1} \mathrm{~K}^{-1}$ for the winds; only those statistically significant at 95\% level are plotted). Only the results for MJO phases 2, 4, 6 and 8 are shown. Full results are available in Figure S11. The conventions

influences in the virtual absence of MJO, while the regression intercept reveal only weak anomalies which may be regarded as noise in our context, as both MJO and ENSO

In the regression coefficients of the boreal winter MJO against ENSO, Figs. 11 and S11, mostly in phases 1-2 and 5-8 as well as in the weak MJO case, there is a dry anomaly in the equatorial Maritime Continent in particular around the island of Borneo and sometimes South India. This feature resembles the impact of El Niño on the boreal summer (JJAS) climate shown in Fig. 12 and shows that ENSO impacts persists throughout most of the life-cycle of the MJO during the boreal summer as is consistent with the anomalous general descent in those regions during El Niño 


\section{WRF MODEL: BOREAL SUMMER (JJAS)}

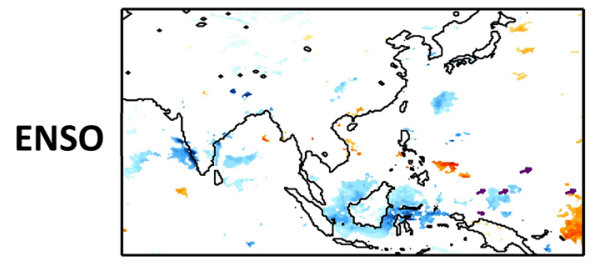

WRF MODEL: BOREAL WINTER (DJFM)

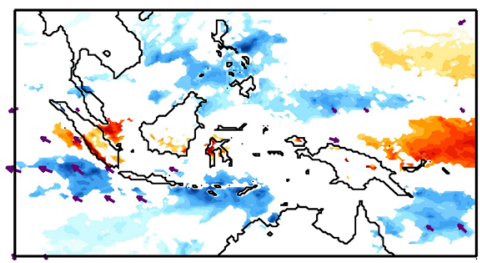

OBSERVATIONS: BOREAL WINTER (DJFM)

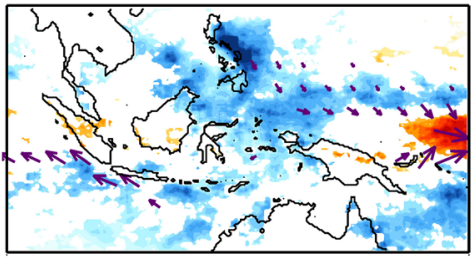

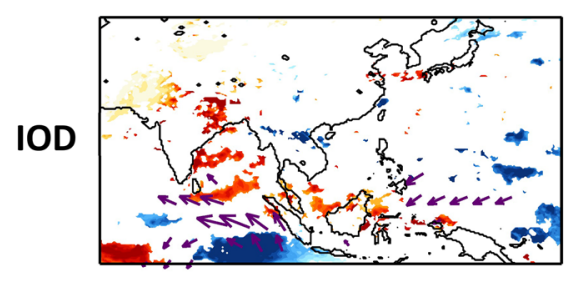
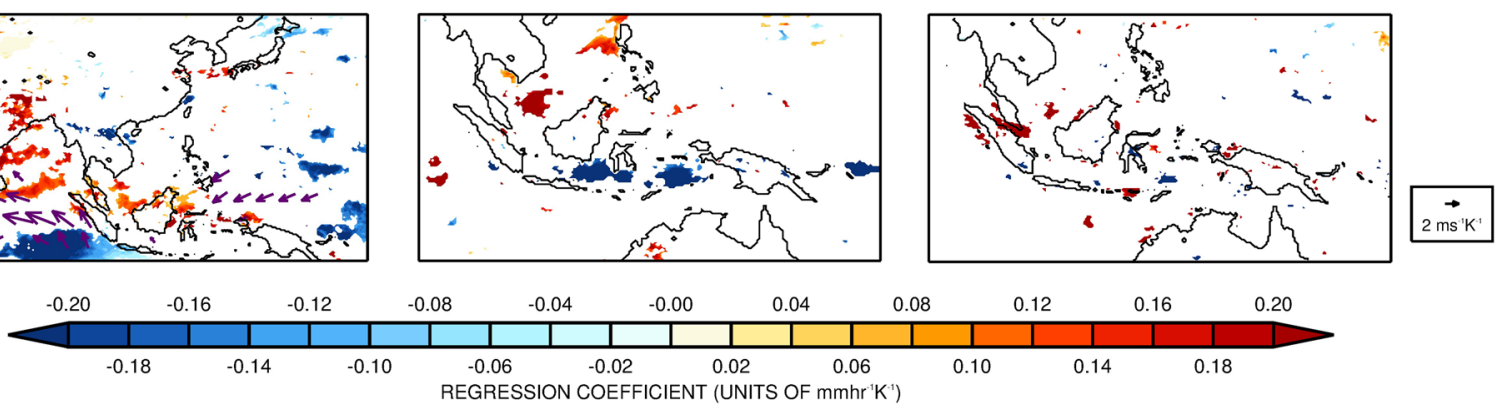

Fig. 12 Linear regression of precipitation rate (shading, $\mathrm{mm} \mathrm{h}^{-1} \mathrm{~K}^{-1}$ ) and $10-\mathrm{m}$ horizontal wind vector (arrows, $\mathrm{m} \mathrm{s}^{-1} \mathrm{~K}^{-1}$ ) against the conventional ENSO and IOD indices for the boreal summer (JJAS) and winter (DJFM) monsoon seasons for the period December 1999-September 2009. Shown are the regression coefficients (only those statistically significant at $90 \%$ level are plotted) for WRF for East Asia

events especially in the Maritime Continent. Comparing the regression coefficients with the regression intercepts, the dry regions becomes generally drier (e.g. in the region between Borneo and New Guinea in phases 6-8, just to the west of the Indian west coast in phase 7 and in parts of the equatorial Maritime Continent in phase 1) and the wet regions becomes generally wetter (e.g. in parts of the South China Sea in phase 4, over the West Pacific to the north and north-east of New Guinea in phases 5 and 6 and around Hainan in phase 1). This regional result is consistent with our earlier finding that the El Niño is generally associated with an increase of the global MJO amplitude during JJAS (Fig. 10).

In DJFM the impact of ENSO seems opposite in the Maritime Continent: as shown by the right half of Figs. 11 and S11: in El Niño events the dry regions tend to get wetter (e.g. from Sumatra to western Borneo in phases 5-7) and the wet regions tend to get drier (e.g. to the south-east of Sulawesi in phases 4-6). But this "destructive interference" of El Niño on the locally wet phases of the MJO in DJFM is not evident in the global MJO amplitude, probably because this feature is unique to the Maritime Continent only. Just like for JJAS, the ENSO impacts on the seasonal mean climate for DJFM (Fig. 12) are generally present throughout the different phases of the MJO and in weak MJO events, demonstrating the robustness of ENSO's impact on the mean Walker circulation over the Maritime Continent against MJO activity and seasons. Qian et al. (2013) reported that in El Niño events $\left(10^{\circ} \mathrm{S}-46^{\circ} \mathrm{N}, 90^{\circ} \mathrm{E}-160^{\circ} \mathrm{E}\right)$ in JJAS and for WRF and observations (TRMM 3B43 for the precipitation rate and QuikScat for the 10-m winds) for Southeast Asia $\left(20^{\circ} \mathrm{S}-20^{\circ} \mathrm{N}, 90^{\circ} \mathrm{E}-160^{\circ} \mathrm{E}\right)$ in DJFM. These panels are a zoomed-in view of the correspondent plots in Fig. 7. The conventions are as in Fig. 2

there is a tendency for enhanced precipitation over the southwestern part of Borneo island and reduced precipitation over the northwestern part. These rainfall anomalies can be seen in the weak MJO cases in Figure S11 with the wetter anomalies having a larger magnitude and being more widespread in MJO phases 6 and 7. As discussed in Qian et al. (2013), the increased precipitation over southwestern Borneo is the result of the convergence between the sea breeze and the anomalous easterly background (large-scale) winds.

Figures 13 and S12 show the regression intercepts and regression coefficients of the boreal summer and winter MJO against the IOD. Although the amplitude of the regression coefficients with respect to IOD is larger than that obtained with respect to ENSO (typically by a factor of 2 from Figs. 11, 13), the impacts of these two modes of inter-annual variability on the MJO (and the BSISO) are comparable as the standard deviation of the IOD index is generally smaller than (typically half) that of the ENSO index. It can be concluded that, like the El Niño, positive IOD events tend to cause the boreal summer MJO to intensify over the Maritime Continent and eastern tropical Indian Ocean as wetter and drier regions tend to get even wetter and drier respectively throughout all phases. On the other hand, during boreal winter, positive IOD events, and also like the El Niño, tend to locally weaken MJO impacts, despite not having a significant influence on the global MJO amplitude. The impact of IOD throughout all MJO phases and for weak 
REGRESSION OF MJO (JJAS) AGAINST IOD

REGRESSION INTERCEPT
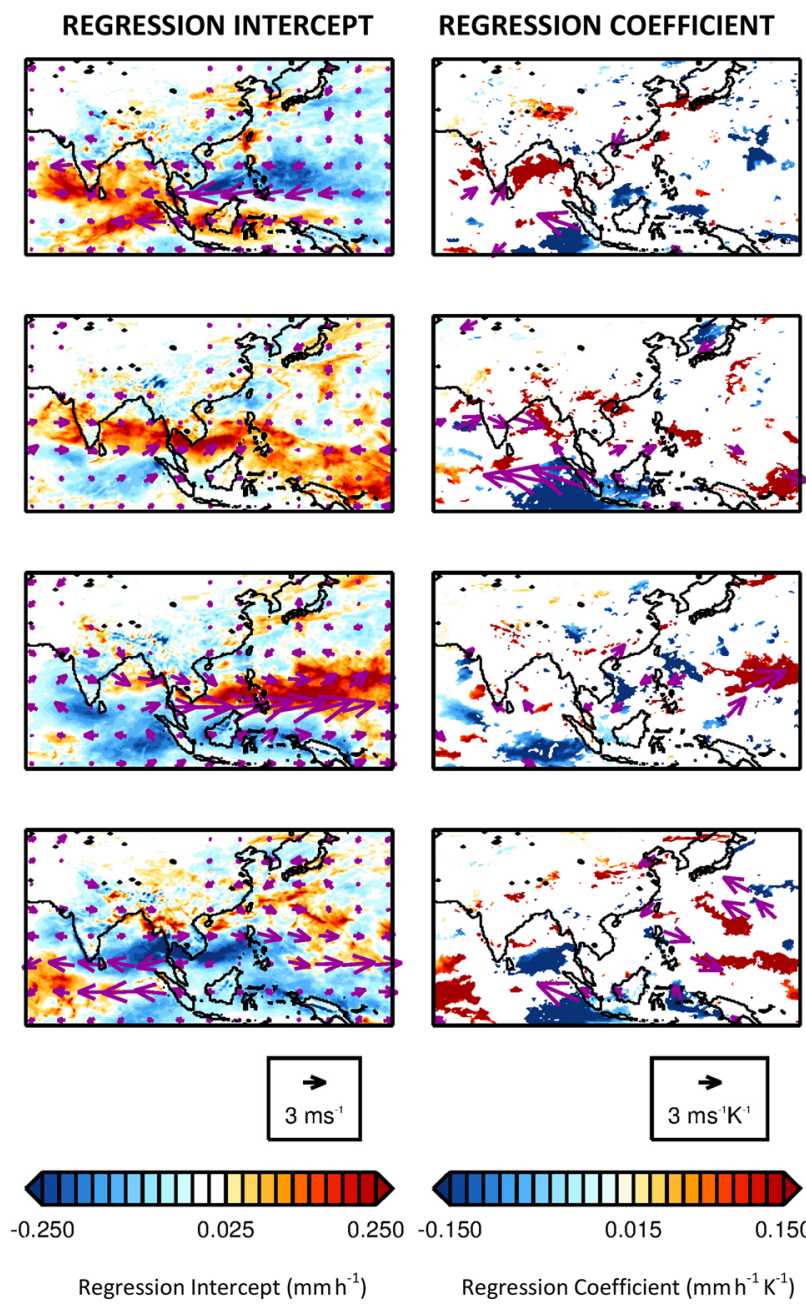

.
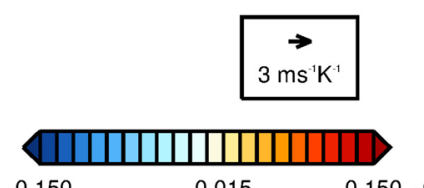

Regression Coefficient $\left(\mathrm{mm} \mathrm{h}^{-1} \mathrm{~K}^{-1}\right)$

\section{REGRESSION OF MJO (DJFM) AGAINST IOD}

REGRESSION INTERCEPT
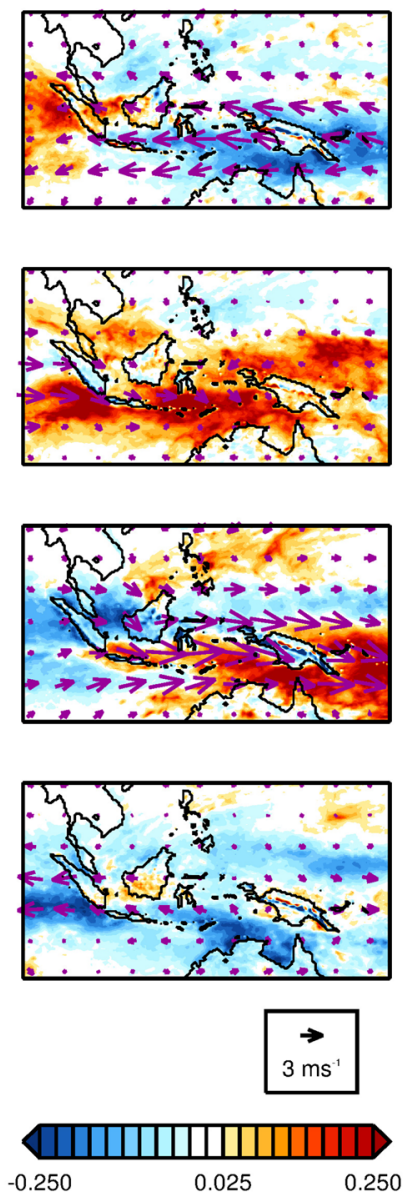

Regression Intercept $\left(\mathrm{mmh}^{-1}\right)$

\section{REGRESSION COEFFICIENT}
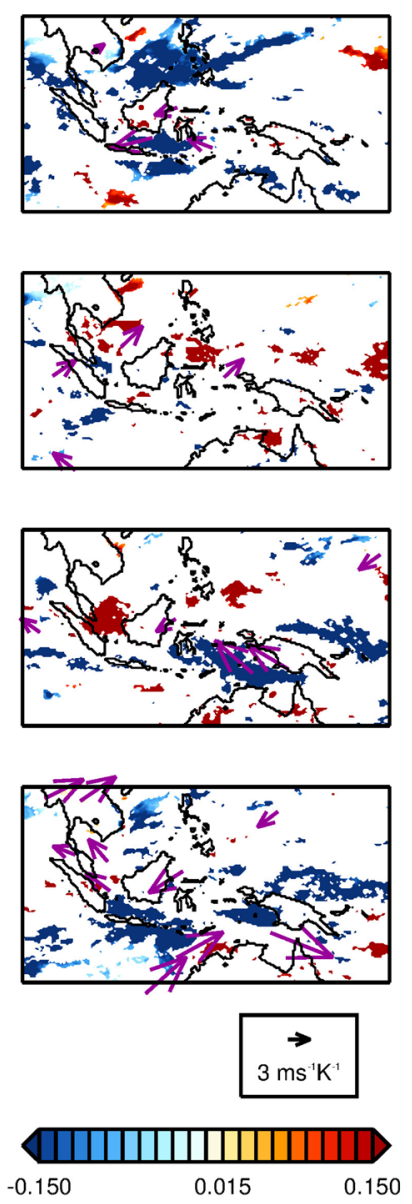

Regression Coefficient $\left(\mathrm{mm} \mathrm{h}^{-1} \mathrm{~K}^{-1}\right)$

Fig. 13 As Fig. 11 but with respect to the IOD index. Full results are available in Figure S12

MJO events generally resembles its impact on the seasonal mean climate given in Fig. 12.

\subsection{Multi-scale interaction through the local diurnal cycle}

In addition to the interaction with the MJO or BSISO through the atmospheric mean state, ENSO and IOD may be able to interact with the MJO or BSISO through modifying the latter's influence with the local diurnal cycle. This is an interaction across at least two spatial (local and regional) and three temporal (3-h, daily and seasonal) scales. By way of example, we shall investigate the ENSO-MJO interaction in DJFM.

First it is important to check whether the WRF model is capable of simulating the observed diurnal cycle. By "diurnal cycle" in this work, we are tacitly referring only to the fundamental harmonic of 1-day period and not higher harmonics. We can express the precipitation anomalies, $P^{\prime}(t)$, with respect to the daily mean as

$P^{\prime}(t)=A \cos \left[\omega_{0}(t-\phi)\right]$

where $A$ is the amplitude, $\phi$ is the phase defined as the time at which the diurnal cycle peaks, and $\omega_{0}=2 \pi /(24 \mathrm{~h})$. In practice, $P^{\prime}(t)$ is estimated by a least-square fit of the expression in Eq. (8) to the long-term average state at each hour of the day. The phase $\phi$ can be converted from UTC to local solar time (LST) in the final step according to the location's longitude $\lambda$ as follows:

$\phi[L S T]=\bmod \left[\left(\phi[U T C]+\frac{24 \mathrm{~h}}{360^{\circ}} \lambda\right), 24 \mathrm{~h}\right]$ 

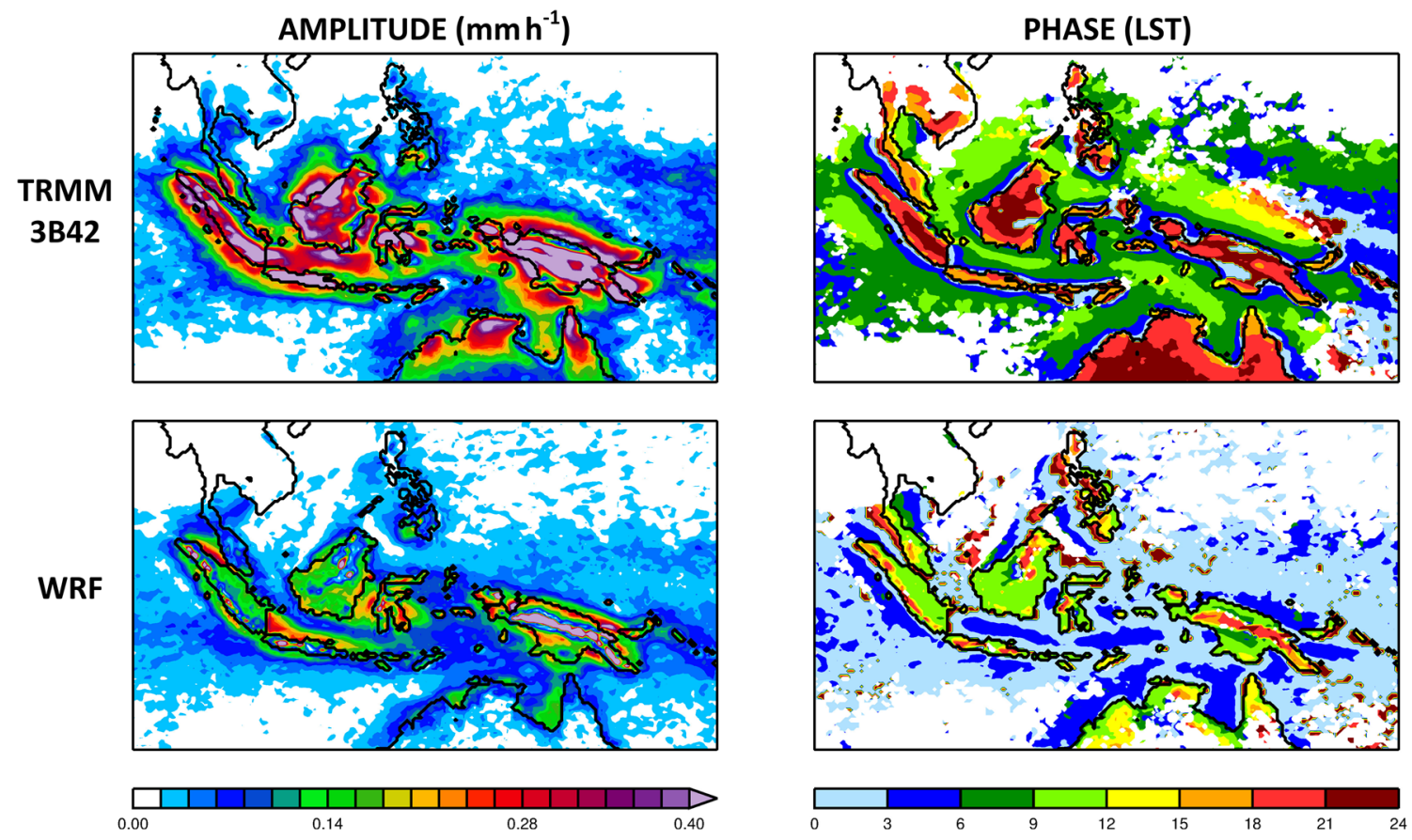

Fig. 14 Amplitude $\left(\mathrm{mm} \mathrm{h}^{-1}\right)$ and phase (peak hour in LST) of the boreal winter (DJFM) precipitation diurnal cycle of TRMM 3B42 (top) and WRF (bottom) for the period 1998-2015. The phase is

Figure 14 shows the amplitude and phase for the TRMM 3B42 and WRF 3-h precipitation rate for DJFM for the common period 1998-2015. As seen, the WRF model does not simulate well the precipitation diurnal cycle: the amplitude is generally underestimated and the phase is shifted earlier by roughly $6 \mathrm{~h}$ over the sea and $9 \mathrm{~h}$ over land. Despite the inability to correctly simulate the phase of the diurnal cycle, WRF is capable of capturing characteristic observed features such as the seaward propagation of rainfall over the coastal seas west of Sumatra, Isthmus of Kra and the Philippines and the quasi-stationary oscillations for rainfall evidenced by the nearly uniform phases in the "wave cavities" (Teo et al. 2011) of the Java Sea, Banda Sea, Timor Sea and Gulf of Carpentaria. The attenuation of the seaward propagation of rainfall in the coastal sea north of New Guinea in WRF, compared to its far seaward extent in TRMM, may be due to the much weaker amplitude of the model's diurnal cycle. The amplitude and phase of the WRF's precipitation diurnal cycle is similar to that obtained with the United Kingdom Met Office Unified Model at $40 \mathrm{~km}$ horizontal grid spacing shown in Love et al. (2011).

The earlier phase of convective rainfall in WRF is a problem that may require modifying the land-atmosphere interaction so that deep convection initiates at the right time in the coastal land before inland and seaward propagation. In our model, the phase of the precipitation diurnal cycle is strongly tied to that of the surface skin temperature updated masked out in regions in which the amplitude of the diurnal cycle does not exceed $0.02 \mathrm{~mm} \mathrm{~h}^{-1}$. The conventions are as in Fig. 2

in the Noah land surface model. Gianotti et al. (2012) also pointed to convective initiation problems in the diurnal cycle of their RegCM3 model. Teo et al. (2011) performed a principal component analysis on the propagating convective signals in the WRF model and showed that the propagation over land is too fast compared to TRMM estimates. Perhaps the propagation could be slowed down by including a parameterized interaction between deep convection and small-scale circulations like gravity currents and gravity waves generated in these coastal rain systems. The potential role played by mechanically forced small-scale circulations on the precipitation diurnal cycle has been noted by Wang and Sobel (2017).

A later onset on coastal land would allow the convective available potential energy (CAPE) to accumulate and the convection to be more intense with more latent heat release later in the day, whereas a slower propagation would lead to more rainfall accumulation and hence increased latent heat release at each location. In both scenarios, the higher latent heat release would drive a stronger diurnal circulation, addressing the amplitude problem in modelling the diurnal cycle as well. Interestingly, despite the poor diurnal cycle, there is little significant bias in the pentad and seasonal model rainfall (cf. Figs. 2, 3, 4), attesting to the control of rainfall by moisture convergence due to regional and not diurnal circulations on sub-seasonal to seasonal timescale. 
Given the deficiencies in the WRF precipitation diurnal cycle, TRMM data will be used instead to investigate the multi-scale interaction. A linear regression of the TRMM 3B42 rainfall rate at each 3-h interval is performed with the daily ENSO index (for the same day in UTC) for each MJO phase during the boreal winter season as follows:

$Y(t, T)=a(t)+b(t) X(T)$

where $Y$ is the rainfall rate anomalies from the daily climatology at $t$ UTC on day $T$ (where $t=00,03,06, \ldots, 21$ ), $X$ is the daily ENSO index, $a$ and $b$ are respectively the regression intercept and coefficient of $Y$ at $t$ UTC against $X$ across all days. $X(T)$ is obtained by applying a monotonic cubic interpolation to the monthly ENSO index from HadISST used before, after assigning the monthly index values to the 1st day of each month. Such an interpolation is justified because daily varying SST is needed for regression but the SST must retain the same ENSO signal as assumed in the work so far. The regression intercept $a$ and coefficient $b$ can be separately approximated by the least-square fit of sinusoidal functions of 1-day period with corresponding amplitudes $\left\{A_{a}, A_{b}\right\}$ and phases $\left\{\phi_{a}, \phi_{b}\right\}$ after subtracting out their respective diurnal means $\{\hat{a}, \hat{b}\}$ such that:

$\left\{\begin{array}{l}a(t)=\hat{a}+A_{a} \cos \left[\omega_{0}\left(t-\phi_{a}\right)\right] \\ b(t)=\hat{b}+A_{b} \cos \left[\omega_{0}\left(t-\phi_{b}\right)\right]\end{array}\right.$

where $\omega_{0}=2 \pi /(24 \mathrm{~h})$.

Taking the mean of Eq. (10) over $t$ while keeping $T$ constant, it is easily seen that $\hat{a}$ and $\hat{b}$ are equivalent to the observed regression intercept and coefficient of the daily mean rainfall rate $\hat{Y}(T)$ against the daily ENSO index $X(T)$ corresponding to what is simulated by WRF in the right half of Fig. 11. The advantage of the simple formulation in Eq. (11) is that the interaction of ENSO with the diurnal cycle, for a given MJO phase, is decomposed into two components: the diurnal cycle across MJO phases under neutral ENSO conditions characterized by $\left(A_{a}, \phi_{a}\right)$ and the perturbation to the diurnal cycle associated with ENSO events characterized by $\left(A_{b}|X|, \phi_{b}\right)$, with the perturbation amplitude being controlled by $|X|$, the strength of the ENSO index. Equation (11) can also be rewritten as follows:

$Y(t)=\hat{a}+\hat{b} X+A_{c}(X) \cos \left\{\omega_{0}\left[t-\phi_{c}(X)\right]\right\}$

such that

$A_{c}(X) e^{-i \phi_{c}(X)} \equiv A_{a} e^{-i \phi_{a}}+X A_{b} e^{-i \phi_{b}}$

The diagnostics $\left(A_{c}, \phi_{c}\right)$ characterize the perturbed diurnal cycle when the ENSO index is $X$ by our linear regression analysis.

The top row of Fig. 15 shows the regression intercept (a) which corresponds to neutral ENSO conditions during weak
MJO activity, decomposed into the daily mean precipitation $(\hat{a})$ as well as the amplitude $\left(A_{a}=A_{W}\right)$ and phase $\left(\phi_{a}=\phi_{W}\right)$ of the diurnal cycle, cf. Equation (11). For the MJO phases 2, 4, 6 and 8 in Fig. 15, the amplitude $\left(A_{a}=A_{M J O}\right)$ and phase $\left(\phi_{a}=\phi_{M J O}\right)$ are expressed respectively as an enhancement factor $\left(A_{M J O} / A_{W}\right)$ and a phase lag $\left(\phi_{M J O}-\phi_{W}\right)$ with respect to the weak MJO conditions (the results for all MJO phases are given in Figure S13). Figures 16 and S14 show moderate El Niño conditions (i.e. $X=+1 \mathrm{~K}$ ), namely the daily precipitation rate $(\hat{b} X)$ and the amplitude enhancement $\left(A_{c}(X) / A_{a}\right)$ and the phase lag $\left(\phi_{c}(X)-\phi_{a}\right)$ of the diurnal cycle.

The first columns of Figs. 15 and 16 are comparable to the right half of Fig. 11 (assuming $X=+1 \mathrm{~K}$ ), apart from differences arising from the masking by statistical significance, implying that despite the failure for WRF to simulate the diurnal cycle well, the anomalies in daily mean precipitation are well captured under different MJO and ENSO conditions. The main exception seems to be for weak MJO activity under neutral ENSO conditions, as the model anomalies are generally positive whereas TRMM anomalies are generally negative because the model winter climatology has a dry bias of about $0.1 \mathrm{~mm} \mathrm{~h}^{-1}$ in the Maritime Continent. This bias is not significant as it contributes less than $12 \%$ of the root-mean-square error in the pentad rainfall (grey shade in Fig. 3) and is not apparent compared to the large rainfall anomalies associated with the MJO.

The daily mean precipitation rate for neutral ENSO conditions in the first column of Figs. 15 and S13 are similar to that in Fig. 5 of Peatman et al. (2014). The active MJO envelope propagates through the Maritime Continent in phases 2-5 and the suppressed envelope in phases 6-1. Figure 15 also shows the "leaping" ahead of the suppressed or active conditions in particular in around parts of Sumatra, Borneo and New Guinea, a well-known feature of the propagation of the MJO through the Maritime Continent: e.g. in phase 2, when the suppressed phase of the MJO is over the Maritime Continent, there is increased precipitation over these islands opposing the regional-scale MJO influence. The opposite is true in phase 4 . The increase in the diurnal cycle amplitude over and to the west of Sumatra in MJO phases 2 and 3 and its subsequent reduction in particular in phases 4-7 is attributed to the interaction between the MJO and local-scale circulations in Fujita et al. (2011).

Comparing the left and middle columns of Figs. 15 and $\mathrm{S} 13$, the diurnal cycle in precipitation over land and coastal seas has a stronger amplitude when the rain-enhancing influence of the MJO is over the locality: e.g. the amplitude is increased in phases 1-3 in parts of Sumatra, 1-4 in Borneo and over the Java Sea and New Guinea in phases 3 and 4. This is consistent with Peatman et al. (2014) and confirms that the MJO daily mean rainfall anomalies are essentially the rectification of the diurnal cycle amplitude onto the mean for a positive definite quantity like rainfall. In the open seas 

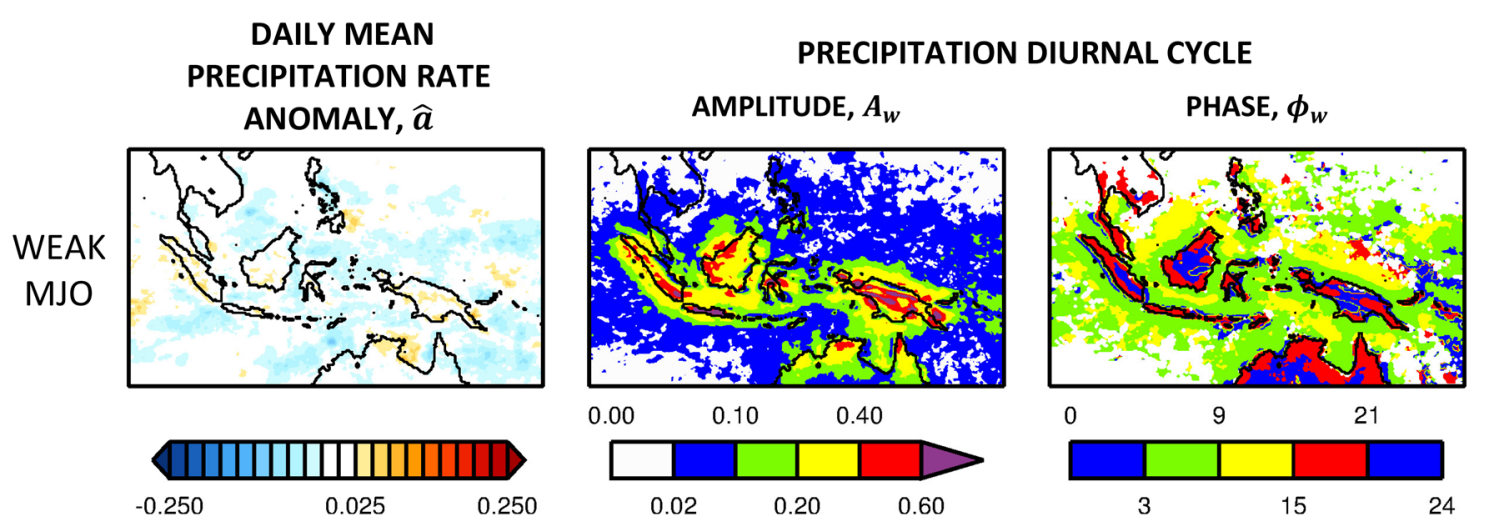

AMPLITUDE

ENHANCEMENT, $A_{M I O} / A_{w}$

PHASE LAG,

$\phi_{M I O}-\phi_{w}$
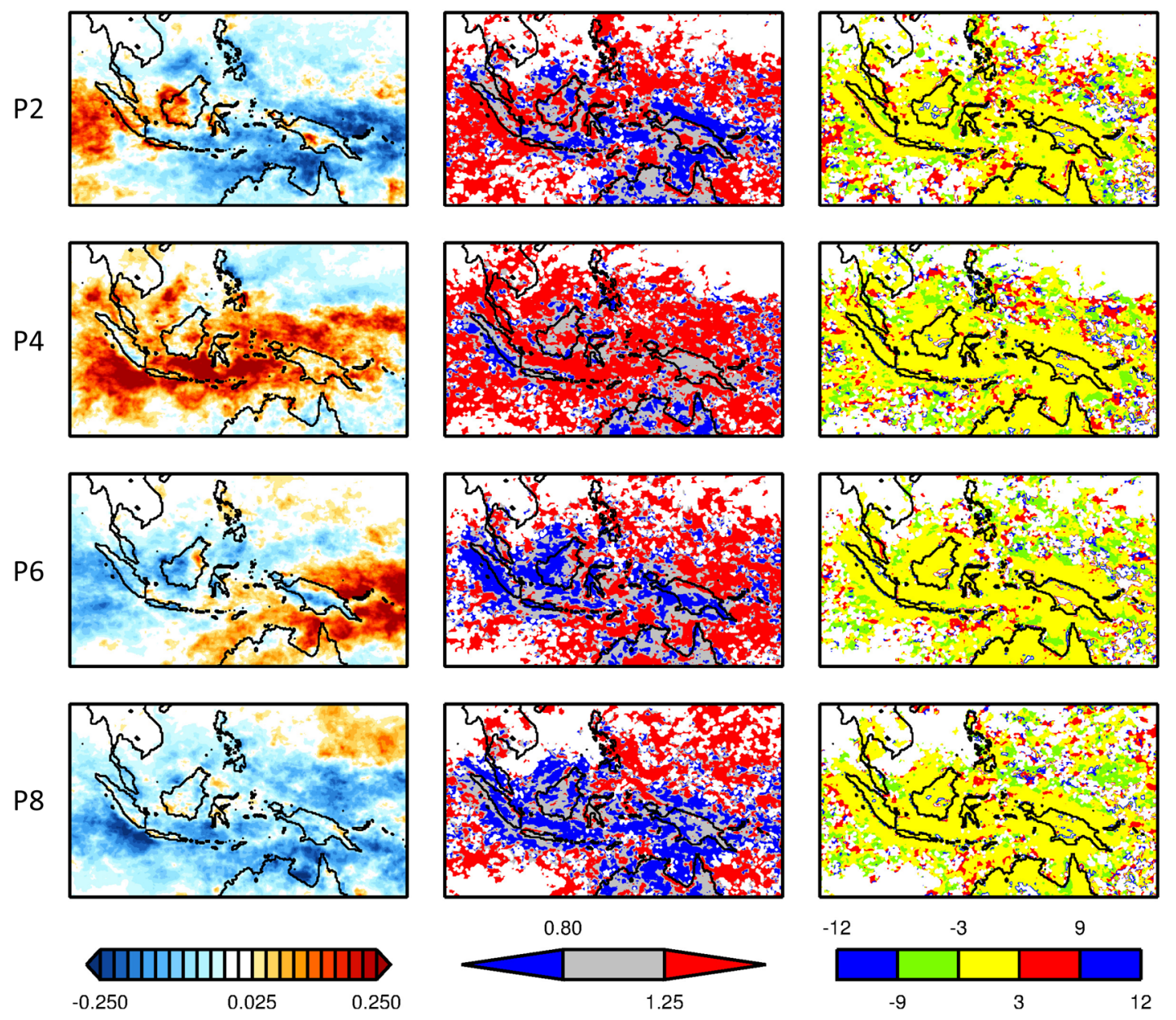

Fig. 15 Intercept of the linear regression of the boreal winter TRMM 3B42 (1998-2015), daily mean precipitation rate anomaly (first column, $\hat{a} ; \mathrm{mm} \mathrm{h}^{-1}$ ) and precipitation diurnal cycle (second and third columns) for MJO phases 2, 4, 6 and 8 and weak MJO with respect to the conventional ENSO index. For weak MJO shown is the amplitude $\left(A_{w} ; \mathrm{mm} \mathrm{h}^{-1}\right)$ and phase $\left(\phi_{w}\right.$; peak hour in LST) with the lat- ter masked out in regions in which the amplitude does not exceed $0.02 \mathrm{~mm} \mathrm{~h}^{-1}$. For the MJO phases shown is the amplitude enhancement $\left(A_{M J O} / A_{w}\right.$; non-dimensional $)$ and phase lag $\left(\phi_{M J O}-\phi_{w}\right.$; hours $)$. The conventions are as in Fig. 2. The results for all MJO phases are given in Figure S13 


\section{DAILY PRECIPITATION RATE ANOMALY, $\widehat{b} X$}
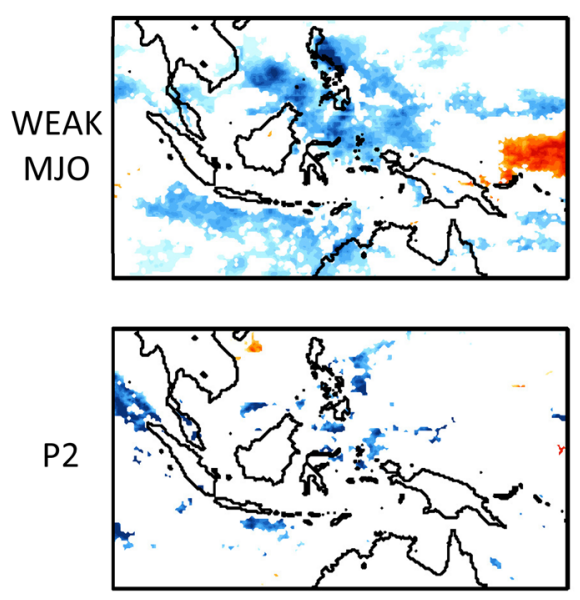

P4
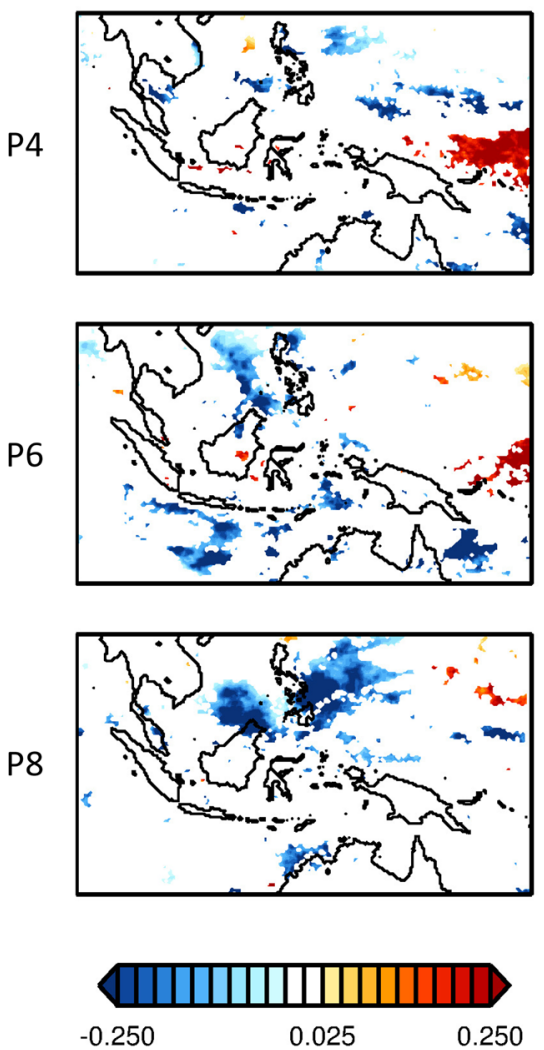

PRECIPITATION DIURNAL CYCLE FOR ENSO INDEX OF $X=+\mathbf{1} K$

AMPLITUDE

ENHANCEMENT, $A_{c}(X) / A_{a}$
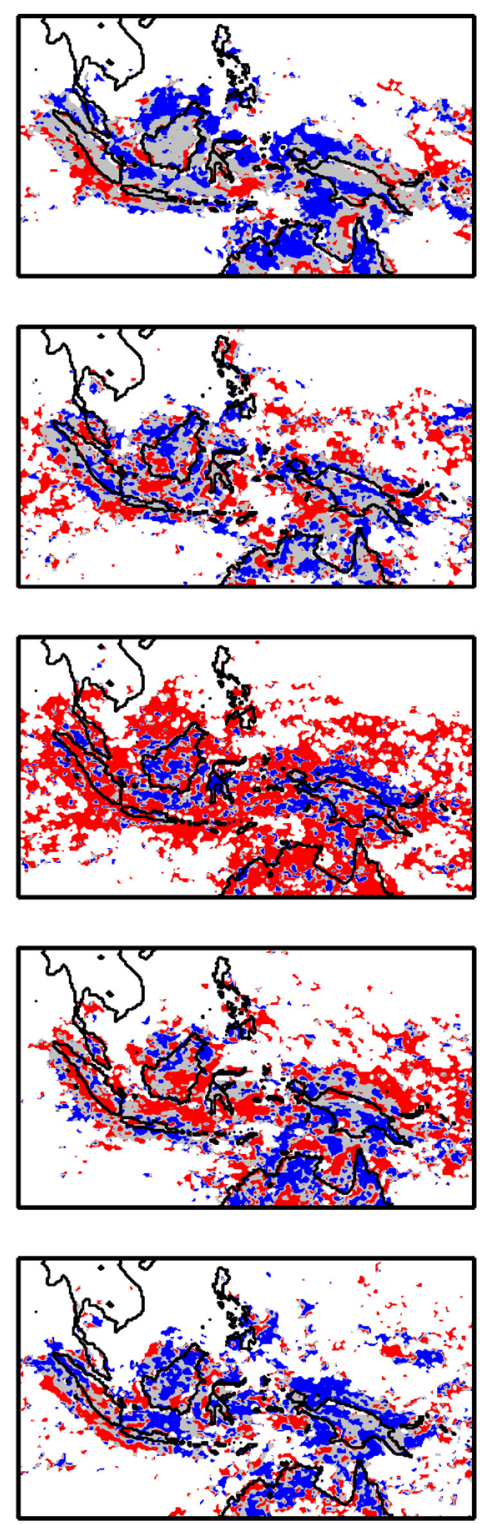

0.80

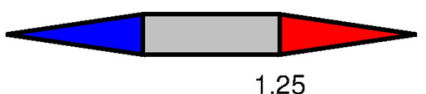

PHASE LAG,
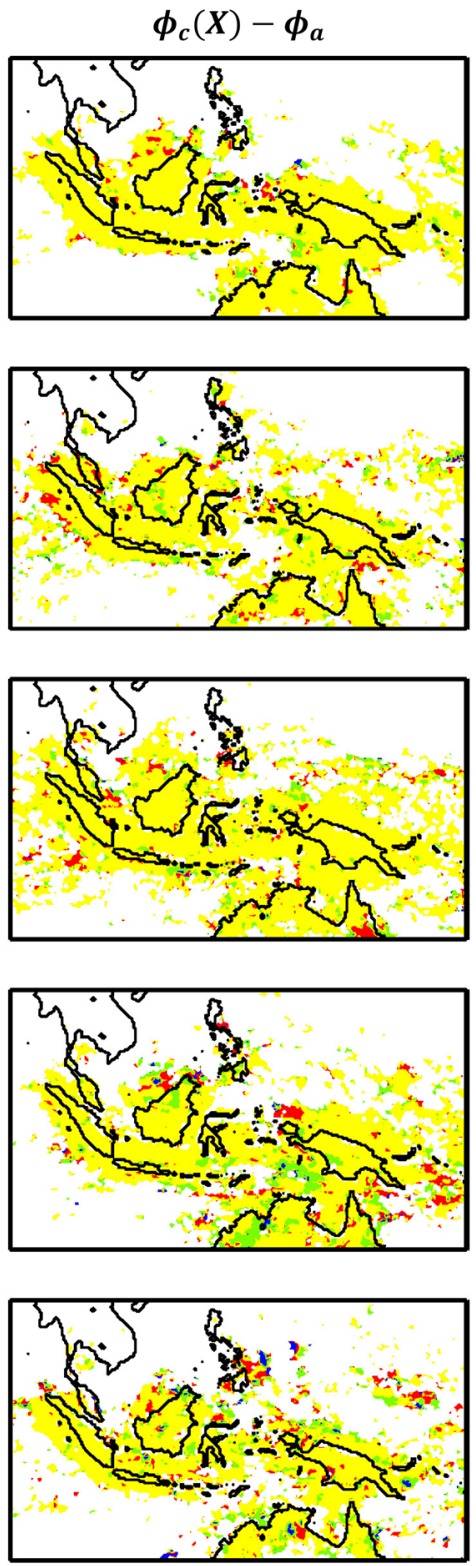

$-12$

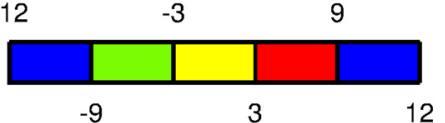

Fig. 16 The first column shows the daily precipitation rate anomaly $\left(\hat{b} X, \mathrm{~mm} \mathrm{~h}^{-1}\right)$ and the second and third columns the amplitude enhancement $\left(A_{c}(X) / A_{a}\right.$, non-dimensional $)$ and phase lag $\left(\phi_{c}(X)-\phi_{a}, \mathrm{~h}\right)$, respectively, for an ENSO index of $X=+1 K$. The daily precipitation rate is only shown in regions where the regres- sion coefficient is statistically significant at the $95 \%$ confidence level whereas the amplitude and phase are only plotted in regions for which the amplitude of the regression intercept given in Fig. 15 exceeds $0.06 \mathrm{~mm} \mathrm{~h}^{-1}$. Only the results for weak MJO and MJO phases 2, 4, 6 and 8 are given. Full results are available in Figure S14 where the diurnal cycle is weak in the first place, the diurnal cycle amplitude is always enhanced by the presence of MJO activity regardless of the MJO phase, even in phase 8 and 1 when the daily mean rainfall is reduced in the open seas. This is understandable as the rainfall over the open seas has a much smaller contribution from the diurnal cycle compared to the diurnal mean and so the mentioned local rectification effect is superseded by regional-scale factors. 
Whereas previous authors focused on the amplitude, we additionally show in the right column of Fig. 15 and S13 that the phase of the diurnal cycle is virtually invariant to the MJO phase, subjected to the time-resolution of the TRMM data, with a late afternoon and early evening peak over land and a morning peak over the sea. Over the open seas, the amplitude of the diurnal cycle is too small rendering the estimation of the diurnal phase unreliable in the least-square fit of a sinusoidal function to the data. From the right topmost panel of Figs. 15 and S13 and the lack of phase lag when the MJO is active, we note the inland progression of the rainfall in Sumatra, Borneo, New Guinea and northern Australia and the seaward propagation of rainfall just offshore of the main islands across all MJO phases and during weak MJO activity. This is consistent with the seasonal mean diurnal cycle shown in top right panel of Fig. 14. In the mountainous areas the diurnal cycle is generally stronger and peaks in the early hours of the day, but this result is constraint by the spatial resolution of TRMM observations which does not resolve well the mountain-valley circulations.

From the right column of Figs. 16 and S14, the phase difference in the diurnal cycle under moderate El Niño is generally less than $3 \mathrm{~h}$, the time-resolution of TRMM's observations, indicating that the influence of ENSO on the precipitation diurnal cycle is mostly on its amplitude for all MJO phases and for weak MJO. Comparison of the amplitude enhancement by ENSO (Fig. 16, middle column) with that by MJO during neutral ENSO conditions (Fig. 15, middle column) reveals that by and large the two change in tandem across the MJO phases where the diurnal amplitudes are significant ( $>0.06 \mathrm{~mm} \mathrm{~h}^{-1}$; unmasked in Fig. 16). For example, in MJO phase 4 (8) where the MJO causes widespread enhancement (reduction) of the diurnal amplitude over land and the coastal seas in Fig. 15, moderate El Niño conditions causes further enhancement (reduction) of the diurnal amplitude in Fig. 16. It seems that moderate El Niño conditions in the Maritime Continent tend to accentuate the

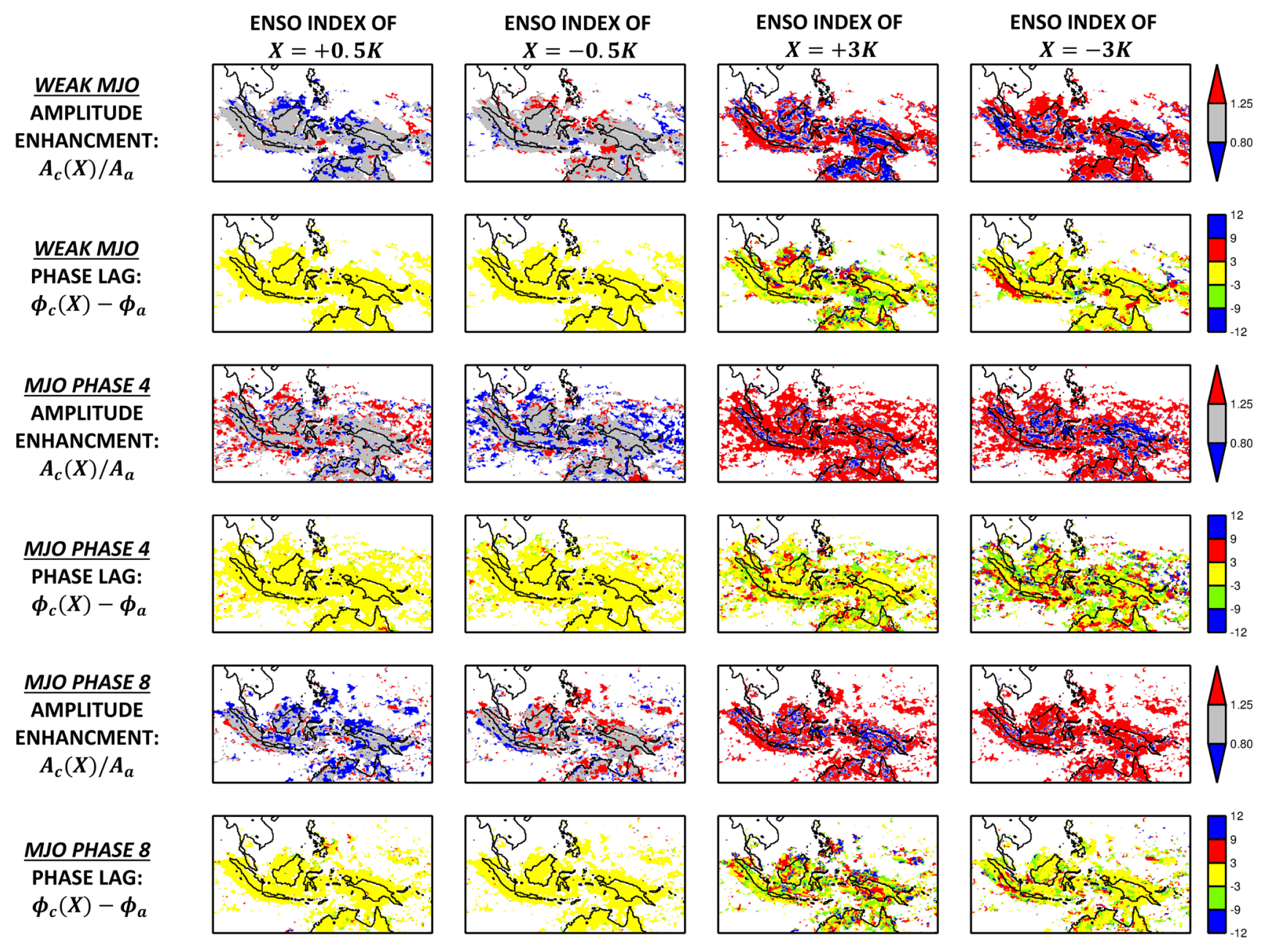

Fig. 17 As Fig. 16 but showing only the amplitude enhancement (non-dimensional) and phase lag (hours) for weak MJO and MJO phases 4 and 8 for an ENSO index of $X= \pm 0.5 \mathrm{~K}$ (borderline El Niño/La Niña) and $X= \pm 3 \mathrm{~K}$ (strong El Niño/La Niña) 
influence of the MJO on the diurnal cycle amplitude, be it enhancing or suppressing. During weak MJO activity, El Niño's modulation of the diurnal cycle amplitude is mostly over the coastal seas, largely in the form of suppression (top middle panel of Fig. 16) perhaps due to cooler SST and lower CAPE. But such modulation, either enhancement or suppression, extends over land under the influence of the MJO across all MJO phases, possibly arising from the multiscale interaction among ENSO, MJO and diurnal circulations, the dynamical nature of which has to be clarified in future investigations.

For a moderate La Niña event $(X=-1 \mathrm{~K}$, not shown), similar results are obtained for the diurnal phase lags but the effect on the diurnal amplitude is generally opposite to that for a moderate El Niño event. Thus, moderate La Niña conditions in the Maritime Continent tend to mitigate the influence of MJO on the diurnal cycle amplitude. However, this result should not be taken for granted because in Eq. (13), $\left(A_{c}, \phi_{c}\right)$ are nonlinear functions of $X$. Figure 17 shows the amplitude enhancement and phase lag for weak El Niño/ La Niña $(X= \pm 0.5 \mathrm{~K})$ and strong El Niño/La Niña $(X= \pm$ $3 \mathrm{~K}$ ) under weak MJO activity and MJO phases 4 and 8 (i.e. respectively when deep and suppressed convection associated with MJO occurs over the region). Weak El Niño and La Niña are practically anti-symmetric in their influence on the diurnal cycle amplitudes and cause little change in the diurnal cycle phases, as shown by the left half of Fig. 17. In fact, ENSO's influence on the precipitation diurnal cycle for all MJO phases or under weak MJO activity is similar for weak to moderate El Niño with the amplitude enhancement scaling up with the strength of the ENSO index (cf. Fig. 16 and left half of Fig. 17). The same is true of weak to moderate La Niña (not shown). The right half of Fig. 17 shows that for strong ENSO events, non-linearity in amplitude and phase sets in such that the anti-symmetry between strong El Niño and La Niña breaks down. For both strong El Niño and La Niña, the diurnal cycle amplitudes are enhanced more than suppressed while phase lags become significant for all MJO phases or under weak MJO activity.

The Argand diagram in Fig. 18 explains the breakdown of the anti-symmetry between El Niño and La Niña modulation of the diurnal cycle as the ENSO index strengthens, where

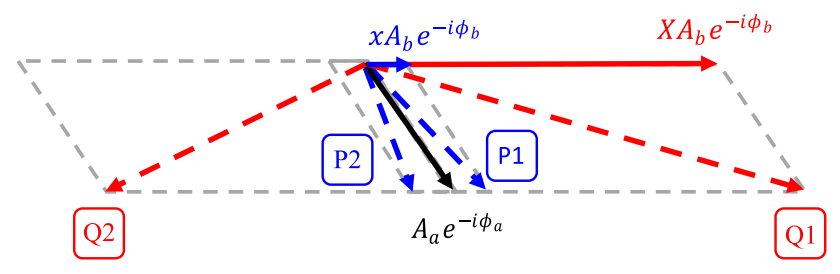

Fig. 18 An Argand diagram showing four complex numbers P1, P2, Q1 and Q2. Refer to the text for the explanation the four complex numbers P1, P2, Q1 and Q2 are defined for $x \ll 1$ and $X \gg 1$ as:

$\mathrm{P} 1 \equiv A_{a} e^{-i \phi_{a}}+x A_{b} e^{-i \phi_{b}}$

$\mathrm{P} 2 \equiv A_{a} e^{-i \phi_{a}}-x A_{b} e^{-i \phi_{b}}$

$\mathrm{Q} 1 \equiv A_{a} e^{-i \phi_{a}}+X A_{b} e^{-i \phi_{b}}$

$\mathrm{Q} 2 \equiv A_{a} e^{-i \phi_{a}}-X A_{b} e^{-i \phi_{b}}$

P1 and P2 characterize the diurnal cycle during weak El Niño and La Niña respectively, whereas Q1 and Q2 characterize the diurnal cycle during strong El Niño and La Niña respectively. From Fig. 18, it is evident that the arguments of $\mathrm{P} 1$ and $\mathrm{P} 2$ approximate to $\phi_{a}$ while $|\mathrm{P} 1|>A_{a}$ and $|\mathrm{P} 2|<A_{a}$, whereas the arguments of Q1 and Q2 are significantly different from $\phi_{a}$ while $|\mathrm{Q} 1|$ and $|\mathrm{Q} 2|$ tend to be larger than $A_{a}$. Thus, as the ENSO index strengthens in magnitude, the phase change of the diurnal cycle becomes significant, while the anti-symmetry of the amplitude modulation breaks down, tending to enhance the diurnal cycle amplitude. Of course, the precise ENSO impact also depends on the values of $\left(A_{a}, \phi_{a}\right)$ and $\left(A_{b}, \phi_{b}\right)$ which are different from location to location.

The results presented here suggest that ENSO, MJO and the precipitation diurnal cycle strongly interact with each other in the Maritime Continent in the boreal winter monsoon season. For neutral ENSO conditions, and over land and costal seas, it is found that the diurnal cycle amplitude increases in tandem with the local rainfall associated with the MJO while there is little change in the phase of the diurnal cycle in line with the results of Peatman et al. (2014). For weak to moderate ENSO events, the impact of ENSO on the diurnal cycle amplitude is mostly linear with little phase change in the diurnal cycle: MJO's influence on the diurnal cycle amplitude is accentuated and mitigated respectively during El Niño and La Niña; under weak MJO activity, El Niño tends to suppress the diurnal cycle while La Niña tends to enhance it. But this amplitude modulation becomes nonlinear for strong ENSO events such as the historic El Niño of 1997-1998: the phase of the diurnal cycle can be significantly altered by ENSO and the amplitude of the diurnal cycle tends to be more enhanced than suppressed for all MJO phases and even when the MJO activity is weak.

\section{Conclusions}

In this paper the interaction of ENSO and IOD with intraseasonal modes of variability such as the MJO and BSISO in Southeast Asia, are investigated in a 27-year downscaling simulation performed with the WRF model in a tropical belt configuration at $36 \mathrm{~km}$ horizontal grid spacing. Although 
the model has been run in this configuration before (e.g. Ray et al. 2011; Hall et al. 2017), to our knowledge this is the first attempt to run WRF for such a long period of time at such spatial resolution that allows a dynamically consistent simulation of both inter-annual and intra-seasonal modes of variability.

In this work, WRF downscales CFSR data with prescribed SSTs and interior nudging applied to the water vapour mixing ratio in the mid-troposphere and to the horizontal wind and potential temperature perturbation in the lower stratosphere. The systematic effect of nudging is to maintain a realistic long-term mean atmospheric state, specifically the seasonal climatology of water vapour and the upper-boundary wind and temperature related to the QBO. It does not lie in the short timescale despite the impression given by the nominal nudging timescale of $1 \mathrm{~h}$. An analysis of the precipitable water budget (in the supplementary material) revealed that the water vapour mixing ratio nudging tendency is far from being the largest term globally and is needed as a simple correction for excessive surface evaporation from the subtropical oceans related to the large error variance in SSKT arising from poor low-cloud simulation.

The results of this work can be summarized as follows:

1. The WRF model with prior improvements to the deep convective rain and cloud schemes (Fonseca et al. 2015; Koh and Fonseca 2016) simulates well the general circulation, precipitation, surface radiative fields, 2-m temperature and soil moisture in the climatology of all four monsoon seasons for the global tropics. The main model biases are enhanced low-level humidity and reduced surface downward short-wave radiation over the oceans. While oceanic surface long-wave radiation and hence SSKT have little biases, there is excessive surface evaporation arising from large error variance in SSKT and the nonlinear relation between temperature and evaporative flux.

2. The influence of ENSO and IOD on the climate of the global tropics is investigated and compared to the coarser-resolution CFSR dataset and the higher-resolution observations. WRF is found to have a similar performance when compared to CFSR, capturing most of the observed features. This suggests that not having regional data assimilation in the tropics (where good-quality observations are sparse compared to the mid-latitudes) is not a limiting problem for regional downscaling, as long as the water vapour budget is well captured in the seasonal climatology. An analysis of the "unusual" co-occurrences of ENSO and IOD (i.e. El Niño events occurring with negative IOD events and vice-versa) revealed the dominant role of ENSO over IOD on the atmospheric state in these events.

3. Life-cycle composites of modelled MJO and BSISO are found to be in close agreement with those observed. While the global MJO index amplitude appears to be affected by the tropical modes of inter-annual variability during JJAS and not DJFM, ENSO and IOD have significant local impacts on the precipitation rate and $850 \mathrm{hPa}$ horizontal wind in both seasons. The global impacts of ENSO and IOD on all phases of both ISOs generally resemble those on the seasonal mean climate, possibly implying that it is through the mean circulation that these lower-frequency events influence the higherfrequency oscillations.

4. Despite the good performance on sub-seasonal to seasonal timescales, the present version of WRF is not able to simulate well the precipitation diurnal cycle in the Maritime Continent: the diurnal cycle amplitude is underestimated and the rainfall peaks earlier by up to $6 \mathrm{~h}$ over the sea and $9 \mathrm{~h}$ over land when compared to TRMM estimates (accurate within $\pm 1.5 \mathrm{~h}$ ). We suggest that either a finer resolution is needed, e.g. down to a few km's eliminating the need for a convective parameterization but increasing the reliance on cloud microphysics and turbulence schemes, or a new generation of parameterized convection that interacts with mesoscale flow fields such as gravity currents and gravity waves in mesoscale convective systems could be developed for WRF.

5. For multi-scale interactions through the local diurnal cycle, TRMM data is investigated instead of WRF outputs. Under neutral ENSO conditions, the amplitude of the diurnal cycle increases when the rain-enhancing influence of the MJO is over a location, mostly over land and the coastal seas, with its phase largely invariant to the MJO phase, and vice versa. For weak to moderate El Niño (La Niña) events, denoted by ENSO index of $+0.5 \mathrm{~K}$ to $+1 \mathrm{~K}(-1 \mathrm{~K}$ to $-0.5 \mathrm{~K})$, the influence of the MJO on the precipitation diurnal cycle amplitudes is accentuated (mitigated) with little effect on the diurnal cycle phases. While weak El Niño and weak La Niña are basically antisymmetric in modifying the influence of MJO on the diurnal cycle amplitudes, strong ENSO events modify non-linearly the influence of MJO on the diurnal cycle breaking down the anti-symmetry between El Niño and La Niña. In the strongest El Niño and La Niña events, the diurnal cycle amplitudes tend to be enhanced more commonly than to be suppressed regardless of the MJO phase or even when the MJO activity is weak. When the MJO activity is weak or absent, weak to moderate El Niño (La Niña) tends to reduce (enhance) the amplitude with little change in the phase of the diurnal cycle.

Given the current limitations of quality observational datasets covering the global tropics at mesoscale resolution, a downscaling type of simulation using a regional model with improved model physics and subjected to substantial verification may be a good alternative approach to investigate multiscale tropical interactions within a dynamically consistent 
framework. The next step may be to run a cloud-permitting model in which the deep convection is resolved explicitly and the topography and coastlines are better represented (Prein et al. 2015). Although attempts to perform such cloud-permitting runs for the global tropics have shown promising results (e.g. Wang et al. 2015; Miura et al. 2007; Satoh et al. 2008), they are relatively short in temporal coverage, lasting for just days to months, given the large computational costs involved. Since the computational power is expected to increase substantially in future, a longer downscaling experiment at cloudpermitting resolution will undoubtedly become a reality. The method of regression analyses among inter-annual, intra-seasonal and diurnal variations in this work can still be applied to those future results to shed more light on multi-scale interactions in the tropics, especially where land-sea and mountainvalley contrasts are concerned.

Acknowledgements This work comprises Earth Observatory of Singapore contribution no. 174. This research is supported by the National Research Foundation Singapore and the Singapore Ministry of Education under the Research Centres of Excellence initiative. We are very grateful to the High Performance Computing Centre (HPCC) at the Nanyang Technological University (NTU) for providing the computational resources needed to perform the numerical experiments presented in this paper and in particular to Hwee Jin (Melvin) Soh and Seng Tat (Edwin) Tan for their support and assistance. We are thankful to Bob Dattore from the University Corporation for Atmospheric Research (UCAR) for his help in downloading the CFSR data through the Computational \& Information Systems Lab Research Data Archive (CISL RDA) website. Special thanks are owed to Brian Hoskins who generously made many constructive suggestions. The WRF code used to produce the 27-year downscaling product presented here is available upon request from the corresponding author. The major modifications made to the WRF code, in particular the precipitating convective cloud (PCC) scheme, have been sent to Jimy Dudhia from the National Center for Atmospheric Research (NCAR) and hopefully will be released in a future version of the model. We would like to thank three anonymous reviewers for their detailed and insightful comments and suggestions that helped to improve the quality of the paper.

Open Access This article is distributed under the terms of the Creative Commons Attribution 4.0 International License (http://creativeco mmons.org/licenses/by/4.0/), which permits unrestricted use, distribution, and reproduction in any medium, provided you give appropriate credit to the original author(s) and the source, provide a link to the Creative Commons license, and indicate if changes were made.

\section{Appendix 1: Verification diagnostics}

$$
\begin{aligned}
& \boldsymbol{D}=\boldsymbol{F}-\boldsymbol{O} \\
& B I A S=\langle\boldsymbol{D}\rangle=\langle\boldsymbol{F}\rangle-\langle\boldsymbol{O}\rangle \\
& \boldsymbol{\mu}=\frac{\langle\boldsymbol{D}\rangle}{\sigma_{D}} \\
& \rho=\frac{1}{\sigma_{O} \sigma_{F}}\langle(\boldsymbol{F}-\langle\boldsymbol{F}\rangle) \cdot(\boldsymbol{O}-\langle\boldsymbol{O}\rangle)\rangle, \quad-1 \leqslant \rho \leqslant 1
\end{aligned}
$$

$\eta=\frac{\sigma_{O} \sigma_{F}}{\frac{1}{2}\left(\sigma_{O}^{2}+\sigma_{F}^{2}\right)}, \quad 0 \leqslant \eta \leqslant 1$

$\alpha=\frac{\sigma_{D}^{2}}{\sigma_{O}^{2}+\sigma_{F}^{2}}, \quad 0 \leqslant \alpha \leqslant 2$

In the equations above, $\mathbf{D}$ is the discrepancy between the model forecast $\mathbf{F}$ and the observations $\mathbf{O} ; \mathbf{X}$ is the mean of $\mathbf{X} ; \sigma_{X}$ is the standard deviation of $\mathbf{X} ; \boldsymbol{\mu}$ is the normalized bias; $\rho$ is the correlation; $\eta$ is the variance similarity; $\alpha$ is the normalized error variance. A random model has $\alpha=1$ so that $\alpha<1$ is recommended. Equation (1) in the main text was derived in Sect. 3.1 of Koh et al. (2012) using the definitions (17) to (19) and the identity,

$\operatorname{VAR}(\boldsymbol{D}) \equiv \operatorname{VAR}(\boldsymbol{F})+\operatorname{VAR}(\boldsymbol{O})-2 \operatorname{COV}(\boldsymbol{F}, \boldsymbol{O})$

where $\operatorname{VAR}(\boldsymbol{X})$ and $\operatorname{COV}(\boldsymbol{X}, \boldsymbol{Y})$ denotes the variance of $\boldsymbol{X}$ and the covariance of $\boldsymbol{X}$ and $\boldsymbol{Y}$ respectively. More information about these diagnostics can be found in Koh et al. (2012).

The model performance in terms of the seasonality of the monthly precipitation is evaluated using the following set of indicators taken from Feng et al. (2013) and Pascale et al. (2015):

$D=\sum_{m=1}^{12} p_{m} \log _{2}\left(\frac{p_{m}}{1 / 12}\right)$

$S=D \frac{R}{R_{M A X}}$

$n^{\prime}=12 \cdot 2^{-D}$

$C=\frac{12}{2 \pi}\left[\arg \left(\sum_{m=1}^{12} p_{m} e^{i \frac{2 \pi m}{12}}\right)\right]$

where $p_{m}$ is the fraction of the total climatological rainfall in a year fallen within the month $m, D$ is the relative entropy of the monthly climatological rainfall distribution, $S$ is the seasonality index ( $S$ is equal to 0 when the precipitation is uniformly distributed throughout the year and is maximised when $R_{M A X}$ is concentrated in a single month and hence $S$ gives information about the distribution of the monthly precipitation), $R$ is the long-term mean of the annual total precipitation at a grid-point, $R_{M A X}$ is the maximum of $\mathrm{R}$ among all grid-points, $n^{\prime}$ is the effective number of wet months (i.e. the number of months over which $p_{m}$ is considerably different from zero: if the precipitation is uniformly distributed throughout the year $D=0 \Rightarrow n^{\prime}=12$ whereas if all the precipitation is concentrated in a single month $\left.D=\log _{2} 12 \Rightarrow n^{\prime}=1\right)$ and $C$ is the centroid of the rainfall 
distribution (i.e. the month with the highest precipitation, giving information about the timing of the wet season for tropical climates).

\section{Appendix 2: Uncertainty in the observations}

Some of the datasets used to evaluate the model's performance also include an estimate of the uncertainty. This estimate is used to mask out regions where the uncertainty in the observations is large. This is accomplished in the following way:

- For a given model field $Z(x, y, t)$, for which the uncertainty in the observations is given by $\delta_{Z}(x, y, t)$, the ratio $R_{Z}$ is computed

$$
R_{Z}(x, y)=\frac{\frac{1}{N_{t}} \sum_{t=1}^{N_{t}} Z(x, y, t)}{\frac{1}{N_{t}} \sum_{t=1}^{N_{t}} \delta_{Z}(x, y, t)}=\frac{\bar{Z}(x, y)}{\overline{\delta_{Z}}(x, y)}
$$

where the average is over the time period considered and $N_{t}$ is the number of time points. The domain-average, $\overline{R_{Z}}$, and standard deviation, $\sigma_{R_{Z}}$, of $R_{Z}$ are then computed;

- Regions for which the condition below is true are considered to have a large observational uncertainty and hence are masked out. The way $S_{Z}$ is defined (i.e. the mean is removed and the absolute value of the difference is then divided by the standard deviation) allows (25) to be applied to any field.

$S_{Z}=\frac{\left|R_{Z}(x, y)-\overline{R_{Z}}\right|}{\sigma_{R_{Z}}}<\phi$

A value of 0.5 is chosen for $\phi$ as for the fields considered, it provides a good compromise between masking out regions for which the uncertainty in the observations is large and still showing the diagnostics over large portions of the domain.

\section{References}

Adler RF, Kidd C, Petty G, Morissey M, Goodman HM (2001) Intercomparison of global precipitation products-the third intercomparison project (PIP-3). Bull Am Meteorol Soc 82:1377-1396

Andrews DG, Holton JR, Leovy CB (1987) Middle atmosphere dynamics. Academic, New York, p 489

Ashok K, Yamagata T (2009) Climate change: the El Niño with a difference. Nature 461:481-484
Ashok K, Behera SK, Rao SA, Weng H, Yamagata T (2007) El Niño Modoki and its possible teleconnection. J Geophys Res 112:C11007. https://doi.org/10.1029/2006JC003798

Behera SK, Yamagata T (2003) Influence of the Indian Ocean Dipole on the southern Oscillation. J Meteorol Soc Jpn 81:169-177

Behera SK, Luo JJ, Masson S, Rao SA, Sakuma H, Yamagata T (2006) A CGCM study on the interaction between IOD and ENSO. J Clim 19:1688-1705

Berry DI, Kent EC (2009) A new air-sea interaction gridded dataset from ICOADS with uncertainty estimates. Bull Am Meteorol Soc 89:1111-1125

Chen F, Dudhia J (2001) Coupling an advanced land surface-hydrology model with the Penn State-NCAR MM5 modeling system. Part I: model implementation and sensitivity. Mon Weather Rev 129:569-585

Chotamonsak C, Salathe EP, Kreasuwan K, Chantara S, Siriwitayakorn K (2011) Projected climate change over Southeast Asia using a WRF regional climate model. Atmos Sci Lett 12:213-219

Chotamonsak C, Salathe EP, Kreasuwan K, Chantara S (2012) Evaluation of precipitation simulations over Thailand using a WRF regional climate model. Chiang Mai J Sci 39:623-638

Dai A, Wigley TML (2000) Global patterns of ENSO-induced precipitation. Geophys Res Lett 27:1283-1286

Davis C, Wang W, Chen SS, Chen Y, Corbosiero K, DeMaria M, Dudhia J, Holland G, Klemp J, Michalakes J, Reeves H, Rotunno R, Snyder C, Xiao Q (2008) Prediction of Landfalling hurricanes with the advanced hurricane WRF model. Mon Weather Rev 136:1990-2005

Dilley M, Heyman BN (1995) ENSO and disaster: droughts, floods and El Niño/Southern oscillation warm events. Disaster 19:181-193

Fan Y, van den Dool H (2008) A global monthly land surface air temperature analysis for 1948-present. J Geophys Res 113:D01103. https://doi.org/10.1029/2007JD008470

Feng X, Porporato A, Rodriguez-Iturbe I (2013) Changes in rainfall seasonality in the tropics. Nat Clim Change 3:811-815. https:// doi.org/10.1038/nclimate1907

Fischer AS, Terray P, Guilyardi E, Gualdi S, Delecluse P (2005) Two independent triggers for the Indian ocean dipole/zonal mode in a coupled GCM. J Clim 18:3428-3449

Fonseca RM, Zhang T, Koh T-Y (2015) Improved simulation of precipitation in the tropics in WRF using a modified BMJ scheme. Geosci Model Dev 8:2915-2928

Fujita M, Yoneyama K, Mori S, Nasuno T, Satoh M (2011) Diurnal convection peaks over the Eastern Indian ocean off sumatra during different MJO phases. J Meteorol Soc Jpn 89:317-330

Gianotti RL, Zhang D, Eltahir EAB (2012) Assessment of the regional climate model version 3 over the maritime continent using different cumulus parameterization and land surface schemes. J Clim 25:638-656

Grell GA, Dudhia J, Stauffer DR (1995) A description of the fifthgeneration Penn State/NCAR Mesoscale Model (MM5). NCAR tech. Note TN-398 + STR, p 117

Hagos S, Leung RL, Dudhia J (2011) Thermodynamics of the MJO in a regional model with constratined moisture. J Atmos Sci 68:1974-1989

Hall NMJ, Thibaut S, Marchesiello P (2017) Impact of the observed extratropics on climatological simulations of the MJO in a tropical channel model. Clim Dyn 48:2541-2555

Hong S-Y, Noh Y, Dudhia J (2006) A new vertical diffusion package with an explicit treatment of entrainment processes. Mon Weather Rev 134:2318-2341

Hsu HH, Lee MY (2005) Topographic effects on the eastward propagation and initiation of the Madden-Julian Oscillation. J Clim 18:795-809

Huffman GJ, Bolvin DT, Nelkin EJ, Wolff DB, Adler RF, Gu G, Hong Y, Bowman KP, Stocker EF (2007) The TRMM multisatellite 
image precipitation analysis (TMPA). Quasi-global, multi-year, combined-sensor precipitation estimates at fine scales. J Hydrometeorol 8:38-55

Iacono MJ, Delamere JS, Mlawer EJ, Shephard MW, Clough SA, Collins WD (2008) Radiative forcing by long-lived greenhouse gases: calculations with the AER radiative transfer models. J Geophys Res 113:D13103. https://doi.org/10.1029/2008JD0099 44

Janjić ZI (1994) The step-mountain eta coordinate model: further developments of the convection, viscous sublayer and turbulence closure schemes. Mon Weather Rev 122:927-945

Jiang L, Li T (2017) Why rainfall response to El Niño over Maritime Continent is weaker and non-uniform in boreal winter than in boreal summer. Clim Dyn. https://doi.org/10.1007/s0038 2-017-3965-6

Joyce RJ, Janowiak JE, Arkin PA, Xie P (2004) CMORPH: a method that produces global precipitation estimates from passive microwave and infrared data at high spatial and temporal resolution. J Hydrometeorol 5:487-503

Koh TY, Fonseca RM (2016) Subgrid-scale cloud-radiation feedback for the Betts-Miller-Janjić convection scheme. QJR Meteorol Soc 142:989-1006

Koh TY, Ng JS (2009) Improved diagnostics for NWP verification in the tropics. J Geophys Res 114:D1202. https://doi. org/10.1029/2008JD011179

Koh TY, Wang S, Bhatt BC (2012) A diagnostic suite to assess NWP performance. J Geophys Res 117:D13109. https://doi. org/10.1029/2011JD017103

Laprise R (2008) Regional climate modeling. J Comput Phys 227:3641-3666

Lee S-Y, McBride JL (2016) The progression of the boreal winter monsoon through the western Maritime Continent as differentiated by ENSO phase. Adv Geosci 42:51-60

Lee J-Y, Wang B, Wheeler MC, Fu X, Waliser DE, Kang I-S (2013) Real-time multivariate indices for the boreal summer intraseasonal oscillation over the Asian summer monsoon region. Clim Dyn 40:493-509

Lestari RK, Koh T-Y (2016) Statistical evidence for asymmetry in ENSO-IOD interactions. Atmos Ocean 54:498-504

Lim K, Hong S (2010) Development of an effective double-moment cloud microphysics scheme with prognostic cloud condensation nuclei $(\mathrm{CCN})$ for weather and climate models. Mon Weather Rev 138:1587-1612

Lo JC, Yang Z, Pielke RA (2008) Assessment of three dynamical downscaling methods using the Weather Research and Forecasting (WRF) model. J Geophys Res 113:D09112. https://doi. org/10.1029/2007JD009216

Love BS, Matthews AJ, Grenville MSL (2011) The diurnal cycle of precipitation over the Maritime Continent in a high-resolution atmospheric model. QJR Meteorol Soc 137:934-947

Madden RA, Julian PR (1971) Description of a 40-50 day oscillation in the zonal wind in the tropical Pacific. J Atmos Sci 28:702-708

Madden RA, Julian PR (1972) Description of global-scale circulation celles in the tropics with a 40-50 day period. J Atmos Sci 29:1109-1123

Madden RA, Julian PR (1994) Observations of the 40-50 day tropical oscillation-a review. Mon Weather Rev 122:814-837

Mason SJ, Goddard L (2001) Probabilistic precipitation anomalies associated with ENSO. Bull Am Meteorol Soc 82:619-638

Miura H, Satoh M, Nasuno T, Noda AT, Oouchi K (2007) A Madden-Julian oscillation event realistically simulated by a global cloud-resolving model. Science 318:1763-1765

Monin AS, Obukhov AM (1954) Basic laws of turbulent mixing in the ground layer of the atmosphere. Trans Geophys Inst Akad Nauk USSR 151:163-187
Moon JY, Wang B, Ha KJ, Lee JY (2012) Teleconnections associated with Northern Hemisphere summer monsoon intraseasonal oscillation. Clim Dyn 40:2761-2774

Pascale P, Lucarini V, Feng X, Porporato A, ul Hasson S (2015) Analysis of rainfall seasonality from observations and climate models. Clim Dyn 44:3281-3301

Peatman SC, Matthews AJ, Stevens DP (2014) Propagation of the Madden-Julian Oscillation through the Maritime Continent and scale interaction with the diurnal cycle of precipitation. QJR Meteorol Soc 140:814-825

Peatman SC, Matthews AJ, Stevens DP (2015) Propagation of the Madden-Julian oscillation and scale interaction with the diurnal cycle in a high-resolution GCM. Clim Dyn 45:2901-2918

Philander SG (1990) El Niño, La Niña, and the Southern Oscillation. Academic, New York, p 292

Prein AF, Langhans W, Fosser G, Ferrone A, Ban N, Klaus G, Keller M, Tölle M, Gutjahr O, Feser F, Brisson E, Kollet S, Schmidli J, Lipzig NPM, Leung R (2015) A review on regional convectionpermitting climate modelling: demonstrations, prospects and challenges. Rev Geophys 53:323-361

Qian J, Robertson AW, Moron R (2013) Diurnal cycle in different weather regimes and rainfall variability over borneo associated with ENSO. J Clim 26:1772-1790

Rasmusson E, Carpenter T (1982) Variation in tropical sea surface temperature and surface wind fields associated with the Southern Oscillation/El Niño. Mon Weather Rev 110:354-384

Ray P, Li T (2013) Relative roles of circumnavigating waves and extratropics on the MJO and its relationship with the mean state. J Atmos Sci 70:876-893

Ray P, Zhang C, Dudhia J, Chen SS (2009) A numerical case study on the initiation of the Madden-Julian oscillation. J Atmos Sci 66:310-331

Ray P, Zhang C, Monscrieff MW, Dudhia J, Caron JM, Leung LR, Bruyere C (2011) Role of the atmospheric mean state on the initiation of the Madden-Julian oscillation in a tropical channel model. Clim Dyn 36:161-184

Rayner NA, Parker DE, Horton EB, Folland CK, Alexander LV, Rowell DP, Kent EC, Kaplan A (2003) Global analyses of sea surface temperature, sea ice, and night marine air temperature since the late nineteenth century. J Geophys Res. https://doi. org/10.1029/2002JD002670

Riciardulli L, Wentz FJ, Smith DK (2011) Remote sensing systems QuikSCAT Ku-2011 monthly ocean vector winds on a $0.25^{\circ}$ grid, Version 4. Remote sensing systems, Santa Rosa, CA. http://www. remss.com/missions/qscat. Accessed 24 Sep 2015

Saha S, Moorthi S, Pan H-L, Wu X, Wang J, Nadiga S, Tripp P, Kistler R, Woollen J, Behringer D, Liu H, Stokes D, Grumbine R, Gayno G, Wang J, Hou Y-T, Chuang H-Y, Juang H-MH, Sela J, Iredell M, Treadon R, Kleist D, Van Delst P, Keyser D, Derber J, Ek M, Meng J, Wei H, Yang R, Lord S, Van Den Dool H, Kumar A, Wang W, Long C, Chelliah M, Xue Y, Huang B, Schemm J-K, Ebisuzaki W, Lin R, Xie P, Chen M, Zhou S, Higgins W, Zou C-Z, Liu Q, Chen Y, Han Y, Cucurull L, Reynolds RW, Rutledge G, Goldberg M (2010) The NCEP climate forecast system reanalysis. Bull Am Meteorol Soc 91:1015-1057

Saha SK, Halder S, Rao AS, Goswami BN (2012) Modulation of ISOs by land-atmosphere feedback and contribution to the interannual variability of Indian Summer Monsoon. J Geophys Res 117:D13101. https://doi.org/10.1029/2011JD017291

Saji NH, Yamagata T (2003) Possible impacts of Indian Ocean Dipole mode events on global climate. Climate Res 25:151-169

Saji NH, Goswami BN, Vinayachandran PN, Yamagata T (1999) A dipole model in the tropical Indian Ocean. Nature 401:360-363

Samala BK, Nagaraju C, Banerjee S, Kaginalkar SA, Dalvi M (2013) Study of the Indian summer monsoon using WRF-ROMS regional coupled model simulations. Atmosph Sci Lett 14:20-27 
Satoh M, Matsuno T, Tomita H, Miura H, Nasuno T, Iga S-I (2008) Nonhydrostatic Icosaheral Atmospheric Model (NICAM) for global cloud resolving simulations. J Comput Phys 227:3486-3514

Seo H, Subramanian AC, Miller AJ, Cavanaugh NR (2014) Coupled impacts of the diurnal cycle of sea surface temperature on the Madden-Julian oscillation. J Clim 27:8422-8443

Skamarock WC, Klemp JB, Dudhia J, Gill DO, Barker DM, Duda MG, Huang X-Y, Wang W, Power JG (2008) A description of the advanced research WRF version 3. NCAR tech. Note TN-4175 STR, $113 \mathrm{pp}$

Stan C (2017) The role of SST variability in the simulation of the MJO. Clim Dyn. https://doi.org/10.1007/s00382-017-3965-6

Steele CJ, Dorling SR, von Glasow R, Bacon J (2013) Idealized WRF model sensitivity simulations of sea breeze types and their effects on offshore windfields. Atmos Chem Phys 13:443-461. https:// doi.org/10.5194/acp-13-443-2013

Tan H, Ray P, Barrett BS, Tewari M, Moncrieff MW (2018) Role of topography on the MJO in the maritime continent: a numerical study. Clim Dyn. https://doi.org/10.1007/s00382-018-4275-3

Tangang F, Salimun E, Aldrian E, Sopaheluwakan A, Juneng L (2017) ENSO modulation of seasonal rainfall and extremes in Indonesia. Clim Dyn. https://doi.org/10.1007/s00382-017-4028-8

Tao W-K, Simpson J, McCumber M (1989) An ice-water saturation adjustment. Mon Weather Rev 117:231-235

Teo C-K, Koh T-Y, Lo JC-F, Bhatt BC (2011) Principal component analysis of observed and modelled diurnal precipitation in the maritime continent. J Clim 24:4662-4675

Tseng W-L, Hsu H-H, Keenylside N, Chang C-WJ, Tsuang B-J, Tu C-Y, Jiang L-C (2017) Effects of surface orography and landsea contrast on the Madden-Julian Oscillation in the Maritime Continent: a numerical study using ECHAM5-SIT. J Clim 30:9725-9741

Tulich SN, Kiladis GN, Suzuki-Parker A (2011) Convectively coupled Kelvin and easterly waves in a regional climate simulation of the tropics. Clim Dyn 36:185-203

Ulate M, Zhang C, Dudhia J (2015) Role of water vapour and convection-circulation decoupling in MJO simulations by a tropical channel model. J Adv Model Earth Syst 7:692-711

Vitart F, Jung T (2010) Impact of the Northern Hemisphere extratropics on the skill in predicting the Madden Julian Oscillation. Geophys Res Lett 37:L23805. https://doi.org/10.1029/2010G L045465
Wagner W, Dorigo W, de Jeu R, Fernandez D, Benveniste J, Haas E, Ertl M (2012) Fusion of active and passive microwave observations to create an Essential Climate Variable data record on soil moisture. In: ISPRS annals of the photogrammetry, remote sensing and spatial information sciences (ISPRS annals), volume I-7, XXII ISPRS congress, Melbourne, Australia, 25 August-1 September 2012, pp 315-321

Wallace JM, Gutzler DS (1981) Teleconnections in the geopotential height field during the Northern Hemisphere winter. J Meteorol Soc Jpn 82:1599-1628

Wang S, Sobel AH (2017) Factors controlling rain on small tropical islands: Diurnal cycle, large-scale wind speed, and topography. J Atmos Sci 44:3515-3532

Wang Y, Xie X (1997) A model for the boreal summer intraseasonal oscillation. J Atmos Sci 54:72-86

Wang Y, Leung LR, McGregor JL, Lee D-K, Wang W-C, Ding Y, Kumura F (2004) Anomalous winter climate conditions in the Pacific rim during recent El Niño Modoki and El Niño events. Clim Dyn 32:663-674

Wang S, Sobel AH, Zhang F, Sun Q, Yue Y, Zhou L (2015) Regional simulation of the October and November MJO events observed during the CINDY/DYNAMO field campaign at gray zone resolution. J Clim 28:2097-2119

Weng H, Ashok K, Behera SK, Rao SA, Yamagata T (2007) Impacts of recent El Niño Modoki on dry/wet conditions in the Pacific rim during boreal summer. Clim Dyn 29:113-129

Weng H, Behera SK, Yamagata T (2009) Anomalous winter climate conditions in the Pacific rim during recent El Niño Modoki and El Niño events. Clim Dyn 32:663-674

Wheeler MC, Hendon HH (2004) An all-season real-time multivariate MJO index: development of an index for monitoring and prediction. Mon Weather Rev 132:1917-1932

Xie S-P, Kaiming H, Hafner J, Tokinaga H, Du Y, Huang G, Sampe T (2009) Indian Ocean capacitor effect on the Indo-Western Pacific climate during the summer following El Niño. J Clim 22:730-747

Žagar N, Gustafsson N, Källén E (2004) Variational data assimilation in the tropics: the impact of background-error constraint. QJR Meteorol Soc 130:103-125

Zeng X, Beljaars A (2005) A prognostic scheme of sea surface skin temperature for modeling and data assimilation. Geophys Res Lett 32:L14605. https://doi.org/10.1029/2005GL023030

Zhang C, Dong M (2004) Seasonality in the Madden-Julian oscillation. J Clim 17:3169-3180 